\title{
Biorefinery-Based Approach to Exploit Mixed Cultures of Lipomyces starkeyi and Chloroidium saccharophilum for Single Cell Oil Production
}

\author{
Gaetano Zuccaro ${ }^{1, *(1)}$, Angelo del Mondo ${ }^{2}(0)$, Gabriele Pinto ${ }^{3}$, Antonino Pollio ${ }^{3}$ and Antonino De Natale ${ }^{3}(1)$ \\ 1 Department of Chemical, Materials and Production Engineering, University of Naples Federico II, \\ 80125 Napoli, Italy \\ 2 Stazione Zoologica Anton Dohrn, Istituto Nazionale di Biologia, Ecologia e Biotecnologie Marine, \\ Villa Comunale, 80121 Napoli, Italy; angelo.delmondo@unina.it \\ 3 Dipartimento di Biologia, Universita' degli Studi di Napoli Federico II, Via Cinthia 26, 80126 Napoli, Italy; \\ gabriele.pinto@unina.it (G.P.); antonino.pollio@unina.it (A.P.); denatale@unina.it (A.D.N.) \\ * Correspondence: gaetano.zuccaro@unina.it
}

check for updates

Citation: Zuccaro, G.; del Mondo, A.; Pinto, G.; Pollio, A.; De Natale, A. Biorefinery-Based Approach to Exploit Mixed Cultures of Lipomyces starkeyi and Chloroidium saccharophilum for Single Cell Oil Production. Energies 2021, 14, 1340. https://doi.org/10.3390/en14051340

Academic Editor: José Carlos Magalhães Pires

Received: 3 January 2021

Accepted: 24 February 2021

Published: 1 March 2021

Publisher's Note: MDPI stays neutral with regard to jurisdictional claims in published maps and institutional affiliations.

Copyright: (c) 2021 by the authors. Licensee MDPI, Basel, Switzerland. This article is an open access article distributed under the terms and conditions of the Creative Commons Attribution (CC BY) license (https:// creativecommons.org/licenses/by/ $4.0 /)$.
Abstract: The mutualistic interactions between the oleaginous yeast Lipomyces starkeyi and the green microalga Chloroidium saccharophilum in mixed cultures were investigated to exploit possible synergistic effects. In fact, microalga could act as an oxygen generator for the yeast, while the yeast could provide carbon dioxide to microalga. The behavior of the two microorganisms alone and in mixed culture was studied in two synthetic media (YEG and BBM $+\mathrm{G}$ ) before moving on to a real model represented by the hydrolysate of Arundo donax, used as low-cost feedstock, and previously subjected to steam explosion and enzymatic hydrolysis. The overall lipid content and lipid productivity obtained in the mixed culture of YEG, BBM + G and for the hydrolysate of Arundo donax were equal to $0.064,0.064$ and $0.081 \mathrm{~g}_{\text {lipid }} \cdot \mathrm{g}_{\text {biomass }}{ }^{-1}$ and $30.14,35.56$ and $37.22 \mathrm{mg}_{\text {lipid }} \cdot \mathrm{L}^{-1} \cdot \mathrm{day}^{-1}$, respectively. The mixed cultures, in all cases, proved to be the most performing compared to the individual ones. In addition, this study provided new input for the integration of Single Cell Oil (SCO) production with agro-industrial feedstock, and the fatty acid distribution mainly consisting of stearic (C18:0) and oleic acid (C18:1) allows promising applications in biofuels, cosmetics, food additives and other products of industrial interest.

Keywords: mixed culture; Lipomyces starkeyi; Chloroidium saccharophilum; Single Cell Oils (SCOs); Arundo donax; biorefinery

\section{Introduction}

A sustainable economic growth, devoted to the future generations, requires long-term available resources for industrial production, in terms of raw materials and energy. Thus, a biorefinery-based approach, aimed to the conversion of low-cost feedstocks into marketable chemicals, fuels and products, has to be preferred [1]. Thus far, several strategies have been explored to enhance the productivity and competitiveness of microbial-based processes and simultaneously improve the biorefinery efficiency [2]. Particular attention has been devoted to the Single Cell Oil (SCO) production or microbial oil synthesis used as supplier of functional oils and for biodiesel [3], but the high fermentation costs make this production still undeveloped industrially. Therefore, the identification of substrates that reduce the costs is considered a solution that positively affects the related industrial implementation as well as the identification of strategies able to contribute positively in the same direction. Among them, co-culturing oleaginous yeasts and microalgae has been studied in recent years for enhancing Single Cell Oil productivity by utilizing minimal resources in various fields such as wastewater treatment, biogas production, enzyme production and bioremediation [4]. While the benefits that can be derived from these systems are clear, the nature of mutualistic interactions between yeast and microalgae 
in co-culture systems are still largely unexplored [5]. The photoautotroph-heterotroph partnership has been defined as able to overcome the high oxygen accumulation that causes a significant problem for microalgal growth especially in closed systems, since it inhibits photosynthesis. Thus, the inclusion of a heterotroph partner able to consume the oxygen mitigates this problem and, at the same time, can contribute to increase microbial biomass and metabolite production [6,7]. In addition, microalgae can convert the dissolved $\mathrm{CO}_{2}$ in the medium into bicarbonate. When it is consumed, releasing $\mathrm{OH}^{-}$ions, it makes the medium alkaline. Conversely, yeast growth results in acidic medium, which can hinder microalgal growth. The combination of both can help to balance this phenomenon [4]. Additionally, the reduction of toxic reactive oxygen species (ROS) by the heterotroph partner has been shown capable of protecting the phototroph microorganisms from oxidative stress in these co-cultures systems [7]. To promote the microbial oil synthesis, it is necessary to provide sufficient organic carbon in culture medium or enhance the photosynthesis of microalgae. The research about the microalgae oil production has been focused mainly on the photoautotrophic growth mode, but there are significant drawbacks associated. In fact, it is difficult to find operating conditions for the simultaneous achievement of biomass accumulation and lipid synthesis during the microalgae life cycle [8]. In addition, light attenuation is unavoidable for photoautotrophic cultures from lab to pilot scale, leading to significant reductions in productivity [9]. For these reasons, other cultivation modes in which microalgae are also able to use the source of organic carbon have been explored to improve the productivity of microbial oils. Oleaginous yeasts can grow in the presence of different carbon sources, for example hexose and pentose sugars, with high growth rates [10]. Generally, they have the ability to accumulate Single Cell Oils (SCOs) at more than $20 \%$ of their total dry weight [11]. In culture medium with high $\mathrm{C} / \mathrm{N}$ ratio, oleaginous microorganisms utilize the remaining carbon source for the synthesis of lipids, mainly triacylglycerols (TAGs). Thus far, yeasts, molds or microalgae have been used for lipid production more frequently than bacteria [12]. Lipomyces starkeyi [13] and Chloroidium saccharophilum (W. Krüger) [14] were chosen as species and their interactions in mixed cultures were investigated. L. starkeyi displays a greater capacity to accumulate lipids and a natural ability to assimilate several feedstocks. It also tolerates low $\mathrm{pH}[15,16]$ and can metabolize inhibitors present in cellulosic hydrolysates [17]. C. saccharophilum was chosen for its high capacity of $\mathrm{CO}_{2}$ assimilation and high tolerance to acidic environments [18], as well as for its high capacity of lipid accumulation [19], which represents positive aspects with regard to the use of mixed cultures to increase the lipid yield but also for the potential use of mixed cultures for $\mathrm{CO}_{2}$ mitigation that would make the process more economically feasible where $\mathrm{CO}_{2}$-rich flue gases are available, i.e., in the vicinity of power plants. Moreover, C. saccharophilum is able to grow under heterotrophic conditions [20] that are not secondary in view of using different feedstocks. It is known that the costs of feedstock represent a bottleneck in the successful development of heterotrophic microbial cultures [21]. For this reason, we adopted a growth medium obtained by Arundo donax L. (Giant reed), a perennial grass largely diffused in the Mediterranean Region. A. donax is considered a promising crop for industrial applications, thanks to its high biomass productivity, its adaptability to different climatic and soil conditions (e.g., polluted or salinized soils) and for the efficient protection offered against the erosion of hilly soils [22]. A. donax hydrolysate has been successfully employed for growing oleaginous yeast strains [23], but, to the best of our knowledge, there are very few studies about mixed oleaginous yeast-microalgae cultures fed with lignocellulosic hydrolysates [4]. This study was performed to verify the presence of synergistic effects comparing the operating conditions and the dynamics of synthetic media inoculated by single and mixed cultures of $L$. starkeyi and C. saccharophilum strains with a real system represented by Arundo donax hydrolysate previously subjected to a steam explosion pre-treatment. The incidence of inhibitors and volatile organic acids was also evaluated. 


\section{Materials and Methods}

\subsection{Strains and Pre-Culture Media}

The oleaginous yeast Lipomyces starkeyi (DBVPG 6193) was supplied by the Dipartimento di Biologia Vegetale di Perugia, Italy. The strains were maintained at $5{ }^{\circ} \mathrm{C}$ on a YPD agar slants and then transferred in YPD medium for the seed culture contained (per liter): yeast extract $10 \mathrm{~g}$, peptone $20 \mathrm{~g}$, D-glucose $20 \mathrm{~g}$ and agar $20 \mathrm{~g}$, when required. Both media were sterilized at $121^{\circ} \mathrm{C}$ for 20 min before use.

The green microalga Chloroidium saccharophilum strain 042 was supplied by the ACUF microalgae collection (http: / / www.acuf.net (accessed on 5 August 2019)) of the Department of Biology, at the University Federico II of Naples, Italy. Single colonies were picked up from the plates and suspended in BBM medium. Tubes and plates were grown at $25{ }^{\circ} \mathrm{C}$ under continuous light supply $\left(100 \mu \mathrm{mol} \cdot\right.$ photons $\left.\cdot \mathrm{m}^{-2} \cdot \mathrm{s}^{-1}\right)$. Once in the exponential phase, each pre-culture was previously diluted with physiological solution and then used as inoculum for the culture media to obtain an initial concentration of approximately $3.0 \times 10^{6}$ cells $\cdot \mathrm{mL}^{-1}$. The two microorganisms share a similar size range in the order of 5-10 micron.

\subsection{Culture Media and Operating Conditions}

Axenic cultures of Lipomyces starkeyi and Chloroidium saccharophilum were grown in $500 \mathrm{~mL}$ Erlenmeyer flasks with an initial volume of $150 \mathrm{~mL}$ which contained (g/L): $\mathrm{KH}_{2} \mathrm{PO}_{4}$ (1.0), $\mathrm{MgSO}_{4} \cdot 7 \mathrm{H}_{2} \mathrm{O}(0.5),\left(\mathrm{NH}_{4}\right)_{2} \mathrm{SO}_{4}(2.0)$, yeast extract (0.5), and glucose (10.0) (YEG). The culture flasks were inoculated, separately and simultaneously, to achieve the initial cell density of about $3.0 \times 10^{6}$ cells $\cdot \mathrm{mL}^{-1}$ for both microorganisms. The $\mathrm{pH}$ was adjusted to $6-6.5$, and, prior to inoculation, the culture medium was sterilized at $121^{\circ} \mathrm{C}$ for $20 \mathrm{~min}$. As seed medium, the Bold Basal Medium (BBM) supplemented with yeast extract and $\left(\mathrm{NH}_{4}\right)_{2} \mathrm{SO}_{4}$ was chosen to replace $\mathrm{NaNO}_{3}$ as nitrogen source and glucose as carbon source $(\mathrm{BBM}+\mathrm{G})$. The medium was autoclaved for $20 \mathrm{~min}$ at $121{ }^{\circ} \mathrm{C}$. The enriched Bold Basal Medium $(\mathrm{BBM}+\mathrm{G})$ medium contained the following components: $\mathrm{CaCl}_{2} \cdot 2 \mathrm{H}_{2} \mathrm{O}\left(1.70 \times 10^{-4} \mathrm{M}\right)$, $\mathrm{KH}_{2} \mathrm{PO}_{4}\left(1.29 \times 10^{-3} \mathrm{M}\right)$, EDTA anhydrous $\left(1.71 \times 10^{-4} \mathrm{M}\right), \mathrm{KOH}\left(5.52 \times 10^{-4} \mathrm{M}\right)$, $\mathrm{K}_{2} \mathrm{HPO}_{4}\left(4.31 \times 10^{-4} \mathrm{M}\right), \mathrm{NaCl}\left(4.28 \times 10^{-4} \mathrm{M}\right), \mathrm{MgSO}_{4} \cdot 7 \mathrm{H}_{2} \mathrm{O}\left(3.04 \times 10^{-4} \mathrm{M}\right), \mathrm{H}_{3} \mathrm{BO}_{3}$ $\left(1.85 \times 10^{-4} \mathrm{M}\right), \mathrm{FeSO}_{4} \cdot 7 \mathrm{H}_{2} \mathrm{O}\left(1.79 \times 10^{-5} \mathrm{M}\right), \mathrm{H}_{2} \mathrm{SO}_{4}\left(1.79 \times 10^{-5} \mathrm{M}\right), \mathrm{ZnSO}_{4} \cdot 7 \mathrm{H}_{2} \mathrm{O}$ $\left(3.07 \times 10^{-5} \mathrm{M}\right), \mathrm{MnCl}_{2} \cdot 4 \mathrm{H}_{2} \mathrm{O}\left(3.07 \times 10^{-5} \mathrm{M}\right), \mathrm{MoO}_{3}\left(4.93 \times 10^{-6} \mathrm{M}\right), \mathrm{CuSO}_{4} \cdot 5 \mathrm{H}_{2} \mathrm{O}$ $\left(6.29 \times 10^{-6} \mathrm{M}\right), \mathrm{Co}\left(\mathrm{NO}_{3}\right)_{2} \cdot 6 \mathrm{H}_{2} \mathrm{O}\left(1.68 \times 10^{-6} \mathrm{M}\right)$, yeast extract $\left(0.5 \mathrm{~g} \cdot \mathrm{L}^{-1}\right),\left(\mathrm{NH}_{4}\right)_{2} \mathrm{SO}_{4}$ $\left(2 \mathrm{~g} \cdot \mathrm{L}^{-1}\right)$ and glucose $\left(10 \mathrm{~g} \cdot \mathrm{L}^{-1}\right)$. The initial $\mathrm{pH}$ was adjusted to $6-6.5$. The flasks were incubated at $25^{\circ} \mathrm{C}$ and under continuous and fluorescent cool white light intensity equal to $100 \mu \mathrm{mol} \cdot$ photons $\cdot \mathrm{m}^{-2} \cdot \mathrm{s}^{-1}$ (36 WT12, Osram Germany). All chemicals were purchased from Sigma-Aldrich. All cultures were carried out in in $500 \mathrm{~mL}$ Erlenmeyer flasks with an initial volume of $150 \mathrm{~mL}$ under continuous agitation. The flasks were sealed with aluminum caps to avoid any contamination from the external environment. The culture flasks were inoculated, separately and simultaneously, to achieve the initial cell density of about $3 \times 10^{6}$ cells $\cdot \mathrm{mL}^{-1}$ for both microorganisms. The synthetic media were compared to lignocellulosic hydrolysate from pretreated Arundo donax. Steam explosion was applied as pretreatment. A. donax (giant reed) was processed in a continuous pilot plant (mod. StakeTech System Digester) located at ENEA-Trisaia Research Centre (Rotondella, Matera, Italy). The biomass was treated processing $150-200 \mathrm{~kg} \cdot \mathrm{h}^{-1}$ of dry biomass, to which water was added to raise the intrinsic humidity up to $50 \%$. The pretreatment was carried out at $210^{\circ} \mathrm{C}$ for $4 \mathrm{~min}$. The severity factor (SF) was determined to be 3.84 according to Equation (1) [24]:

$$
S F=\log \left(t \times \mathrm{e} \frac{T-100}{14.75}\right)
$$

where $t$ is the residence time in minutes, $T$ is the temperature of pre-treatment, 100 is the reference temperature and 14.75 is an arbitrary constant.

Pretreated Arundo donax was mixed with distilled water ( $\mathrm{pH}$ 5.2) to obtain a solution with $5 \% w / v$ solid content and was afterwards treated with commercial enzymes purchased 
from Sigma-Aldrich consisting of cellulase from Trichoderma reesei ATCC 26921 (15 FPU/g of cellulose) and $\beta$-glucosidase from Aspergillus niger (30 CBU/g of cellulose). Cellulase activity was measured following the NREL filter paper assay [25] and reported in filterpaper units (FPU) per milliliter of solution. $\beta$-glucosidase activity was measured using the method described by Wood and Bhat [26] and reported in cellobiase units (CBU). Enzymatic hydrolysis was carried out at $160 \mathrm{rpm}$ and $50^{\circ} \mathrm{C}$ for $48 \mathrm{~h}$ (Minitron, Infors HT, Switzerland). The initial $\mathrm{pH}$ was adjusted to 6-6.5. As the hydrolysate of Arundo donax $(\mathrm{ADH}), 8 \mathrm{~mL}$ of phosphate buffer $(0.2 \mathrm{M})$ were added, and then it was inoculated with Lipomyces starkeyi and Chloroidium saccharophilum alone and mixed to achieve the initial cell density of $3.0 \times 10^{6}$ cells $\cdot \mathrm{mL}^{-1}$ for both microorganisms. All tests were carried out in triplicate and the standard deviation was calculated on the biological triplicate.

\subsection{Analytical Methods}

Measurements of $\mathrm{pH}$ were made by an inoLab ${ }^{\circledR}$ Multi 740 Multimeters pH-meter (WTW). The optical density was monitored with a Shimadzu UV6100 spectrophotometer (Japan) and by measuring turbidity of liquid samples at 600 and $680 \mathrm{~nm}$. Microbial biomass $\left(\mathrm{g} \cdot \mathrm{L}^{-1}\right)$ was determined by filtering $2-3 \mathrm{~mL}$ of culture over pre-weight PES filters $(0.45 \mu \mathrm{m}$; Sartorius Biolab, Göttingen, Germany). The retained biomass on filters was washed, dried at $105^{\circ} \mathrm{C}$ for $24 \mathrm{~h}$ and then stored in a desiccator before being weighed. The individual cell counts of yeast and microalga were determined with a hemocytometer, using the microscope, due to the different appearance of L. starkeyi and C. saccharophilum being different under the microscope. After centrifugation and filtration with $0.2 \mu \mathrm{m}$ cut-off filters, the liquid samples were analyzed for residual substrate content (glucose) and soluble fermentation products (VFA, alcohols). Glucose and VFAs were analyzed by HPLC (LC2010, Shimadzu, Japan), equipped with a refractive index detector (RID-20A, Shimadzu, Japan). Samples were first centrifuged at $12,000 \mathrm{~g}$ for $15 \mathrm{~min}$ and then supernatants were filtered with $0.2 \mu \mathrm{m}$ syringe filters. HPLC analysis were performed at a flow rate of $0.7 \mathrm{~mL} / \mathrm{min}$ on an Aminex HPX-87H, $300 \times 7.8 \mathrm{~mm}$ (Bio-Rad) column at a temperature of $35^{\circ} \mathrm{C} . \mathrm{H}_{2} \mathrm{SO}_{4}$ at $4 \mathrm{mM}$ was used as the mobile phase. The total concentration of phenolic compounds was determined using Folin-Ciocalteu assay [27]. A simple method based on UV spectra was followed for the estimation of total furans (furfural and hydroxymethylfurfural) in the hydrolysates [28]. Lipids were extracted following a method adapted from Bligh and Dyer [29]. The samples were stirred in a $\mathrm{CHCl}_{3} / \mathrm{CH}_{3} \mathrm{OH}$ mixture $(2: 1 \mathrm{w} / \mathrm{v})$ over $24 \mathrm{~h}$, and the oleaginous biomass was filtered off and washed with additional $\mathrm{CHCl}_{3}$. This procedure was repeated three times. The solvent was then removed by evaporation under $\mathrm{N}_{2}$ stream. The total lipid concentration was estimated by gravimetric method. To calculate the lipid concentration of the cells, they were dried to a constant weight in the oven at $80^{\circ} \mathrm{C}$. The lipids extracted were subjected to transesterification reaction in a stirred container at $60^{\circ} \mathrm{C}$ for $10 \mathrm{~min}$, using $\mathrm{NaOH}(1 \% w / v)$ as catalysts and methanol as reagent. The samples were dried by $\mathrm{N}_{2}$ stream and subsequently $1 \mathrm{~mL}$ of heptane was added for the analysis. The content of fatty acid methyl esters was determined by gas chromatography. The GC (GC-MS 2010, Shimadzu, Japan) was equipped with a flame ionization detector and an Omegawax 250 (Supelco) column ( $30 \mathrm{~m} \times 0.25 \mathrm{~mm}$ I.D., $0.25 \mu \mathrm{m})$. Helium was used as carrier gas (flow rate: $30 \mathrm{~mL} / \mathrm{min}$ ). The FAME samples were initially dissolved in $1 \mathrm{~mL}$ of heptane and $1 \mu \mathrm{L}$ of this solution was loaded onto the column. The temperature of the column was kept at $50{ }^{\circ} \mathrm{C}$ for $2 \mathrm{~min}$, then heated to $220^{\circ} \mathrm{C}$ at a rate of $4{ }^{\circ} \mathrm{C} / \mathrm{min}$ and finally kept constant for $2 \mathrm{~min}$. Methyl decanoate was used as internal standard. The peak of each methyl ester was identified by comparing the retention time with the peak of the pure standard compound.

\subsection{Parameter Analysis}

The specific growth rate $\left(\mu_{x}\right)$ and yield factor $\left(Y_{x / s}\right)$ were calculated according to Equations (2)-(4):

$$
\frac{d X}{d t}=\mu X
$$




$$
\begin{gathered}
\mu_{x}=\left[\ln \left(X_{t} / X_{0}\right)\right] /\left(t-t_{0}\right) . \\
Y_{x / s}=\frac{X-X_{0}}{S_{0}-S}
\end{gathered}
$$

where $X$ and $X_{0}$ are the concentrations of microbial biomass at time $t$ and at initial time, respectively. $\mu_{x}$ is the specific growth rate of microbial biomass. $S_{0}$ and $S$ are the values of substrate concentrations at initial time and during the cultivation time, respectively. Lipid content, lipid yield $\left(Y_{\text {lipid }}\right)$ and lipid productivity were calculated according to Equations (5)-(7), respectively:

$$
\begin{gathered}
\text { Lipid content }\left[g_{\text {lipid }} \cdot g_{\text {biomass }}{ }^{-1}\right]=\frac{m_{\text {lipid }}}{m_{\text {microbial biomass }}} \\
Y_{\text {lipid }}\left[g_{\text {lipid }} \cdot L^{-1}\right]=\frac{m_{\text {lipid }}}{V} \\
\text { Lipid productivity }\left[\mathrm{mglipid}_{\text {lid }} \cdot L^{-1} \cdot d^{-1}\right]=\frac{m_{\text {lipid }}}{\Delta t}
\end{gathered}
$$

Lipid content is the total lipid amount divided by the total microbial biomass. The lipid yield $\left(Y_{\text {lipid }}\right)$ is the lipid concentration, i.e., the mass of lipids on the (same) volume of culture. Lipid productivity is defined as the concentration obtained in relation to cultivation time.

\section{Results and Discussion}

\subsection{Effects of Synthetic Media on C. saccharophilum and L. starkeyi Growth Performances in Mono and Mixed Culture}

A preliminary experimental campaign was conducted to evaluate the behavior of the two pure strains selected for this study, L. starkeyi and C. saccharophilum, in two different synthetic media, $\mathrm{BBM}+\mathrm{G}$ (Figure $1 \mathrm{a}-\mathrm{c}$ ) and YEG (Figure $2 \mathrm{a}-\mathrm{c}$ ), at a $\mathrm{C} / \mathrm{N}$ ratio equal to 11 , which was not very different from the Redfield one equal to about 7 [30], and thus avoiding initial $\mathrm{N}$ limitations. Tests were performed by inoculating each batch with single or mixed cultures. In this latter case, the inoculum ratio between the yeast and the microalga was 1:1. No evidence was observed in terms of microbial biomass and cell proliferation, even changing this ratio, as demonstrated in a previous study [31]. In addition, an increase in the microalga:yeast ratio would promote algal metabolic activity by inducing an increase in $\mathrm{pH}$, which could inhibit yeast growth. In BBM $+\mathrm{G}$, the growth of $C$. saccharophilum showed an initial trend correlated to the glucose consumption (Figure 1a). This could be justified by an initial photosynthetic activity lower than the metabolism of organic carbon, which could produce an endogenic source of $\mathrm{CO}_{2}$ [31], reducing the $\mathrm{CO}_{2}$-limiting effect and explaining the increase in microbial biomass once the predominantly heterotrophic metabolism has stopped in the latter part of the cultivation time (Figure 1a). In the meantime, the reduced cell proliferation一from $2.7 \times 10^{7}$ to $3.6 \times 10^{7}$ cells $\cdot \mathrm{mL}^{-1}$ —would presuppose an increase in size more than in number, due to a phase of lipid accumulation. This hypothesis seemed to be confirmed by the trend of microbial biomass, which increased from 0.93 to $2.3 \mathrm{~g} \cdot \mathrm{L}^{-1}$ (Figure 1a). The biomass growth rate $\left(\mu_{x}\right)$, the related value of biomass productivity and the yield factor $\left(Y_{x / \mathrm{s}}\right)$, equal to $0.381 \mathrm{~d}^{-1}, 328.6 \mathrm{mg} \cdot \mathrm{L}^{-1} \cdot \mathrm{day}^{-1}, 0.471 \mathrm{~g} \cdot \mathrm{g}^{-1}$, respectively (Table 1), are comparable with the values obtained by Herrera-Valencia et al. and Tan and Johns $[19,20]$, taking into account the different growth conditions. The single cultures of $L$. starkeyi did not show any growth (Figure $1 \mathrm{~b}$ ), despite the presence of yeast extract and glucose. The initial glucose consumption probably led to the production of ethanol and acetic acid due to a reduced activity of TCA-cycle, that, in turn, moved the culture to anaerobiosis, due to oxygen limitation in the medium, essential for glucose transport. The batch culture of $L$. starkeyi was exposed to transient fermentation inhibition (Custers effect), and the absence of an alternative oxygen-independent transport mechanism for glucose absorption led to the lack of microbial growth [32]. Figure 1c shows the performances of $C$. saccharophilum and L. starkeyi grown in mixed cultures. From the trends associated to the cell proliferation, it seemed evident the presence of a synergistic effect, as evidenced by the 
comparison of glucose consumption rate values. The microalga was able to provide the oxygen necessary for L. starkeyi to metabolize the glucose, which was partially assimilated by $C$. saccharophilum and this effect led to an increase of glucose consumption rate from $1.47 \mathrm{~g} \cdot \mathrm{L}^{-1} \cdot$ day $^{-1}$ for $C$. saccharophilum alone to $2.15 \mathrm{~g} \cdot \mathrm{L}^{-} \cdot$ day $^{-1}$ for mixed culture. The final constant values in terms of cell concentration (Figure 1c) are justified by the metabolic shift due to an imbalance in the $\mathrm{C} / \mathrm{N}$ ratio, which induced lipid accumulation phase rather than cell duplication. Since the microbial biomass productivity is a result of gravimetric methodology, the relative value increased from $328.6 \mathrm{mg} \cdot \mathrm{L}^{-1} \cdot$ day $^{-1}$ for $C$. saccharophilum alone to $366.2 \mathrm{mg} \cdot \mathrm{L}^{-1} \cdot$ day $^{-1}$ for mixed culture (Table 1). An increase was also observed in the specific growth rate, but not in the yield factor $\left(Y_{x / s}\right)$, which is likely affected by endogenous metabolism and a faster glucose consumption. In mixotrophic conditions, the microalga should be less dependent on the yeast for $\mathrm{CO}_{2}$, whereas the latter still benefits from the alga for $\mathrm{O}_{2}$ production, which is partially consumed by respiration of the alga, negatively affecting yeast growth. However, this aspect did not affect the metabolic activity of the yeast, which, on the contrary, was favored by the presence of alga (Figure $1 \mathrm{~b}, \mathrm{c}$ ). Comparing the max values of cells $\cdot \mathrm{mL}^{-1}$ for $C$. saccarophilum alone and in mixed culture $\left(3.6 \times 10^{7}\right.$ and $5.8 \times 10^{7}$ cells $\cdot \mathrm{mL}^{-1}$, respectively), it emerges that the trend is similar; therefore, there was no real competition for $\mathrm{N}$ or $\mathrm{P}$ sources or an effective reduced production of $\mathrm{O}_{2}$ by the microalga, necessary to metabolize glucose, which would otherwise have been the reason for a reduced growth of yeast as well. Moreover, the yeast proliferation has undoubtedly induced a progressive photo-inhibition effect which could be another reason for a slowdown of microalgal growth in the final part of the test. The latter effect was associated to a limiting $\mathrm{O}_{2}$ concentration, which in turn did not allow the yeast to grow further and to produce $\mathrm{CO}_{2}$ available to the microalga. Tests were carried out in an attempt to verify the behavior of $L$. starkeyi alone in a more suitable medium, classified as YEG since it was found to be unable to grow in a BBM $+G$ medium, although enriched with yeast extract and glucose because of the Custers effect discussed above.

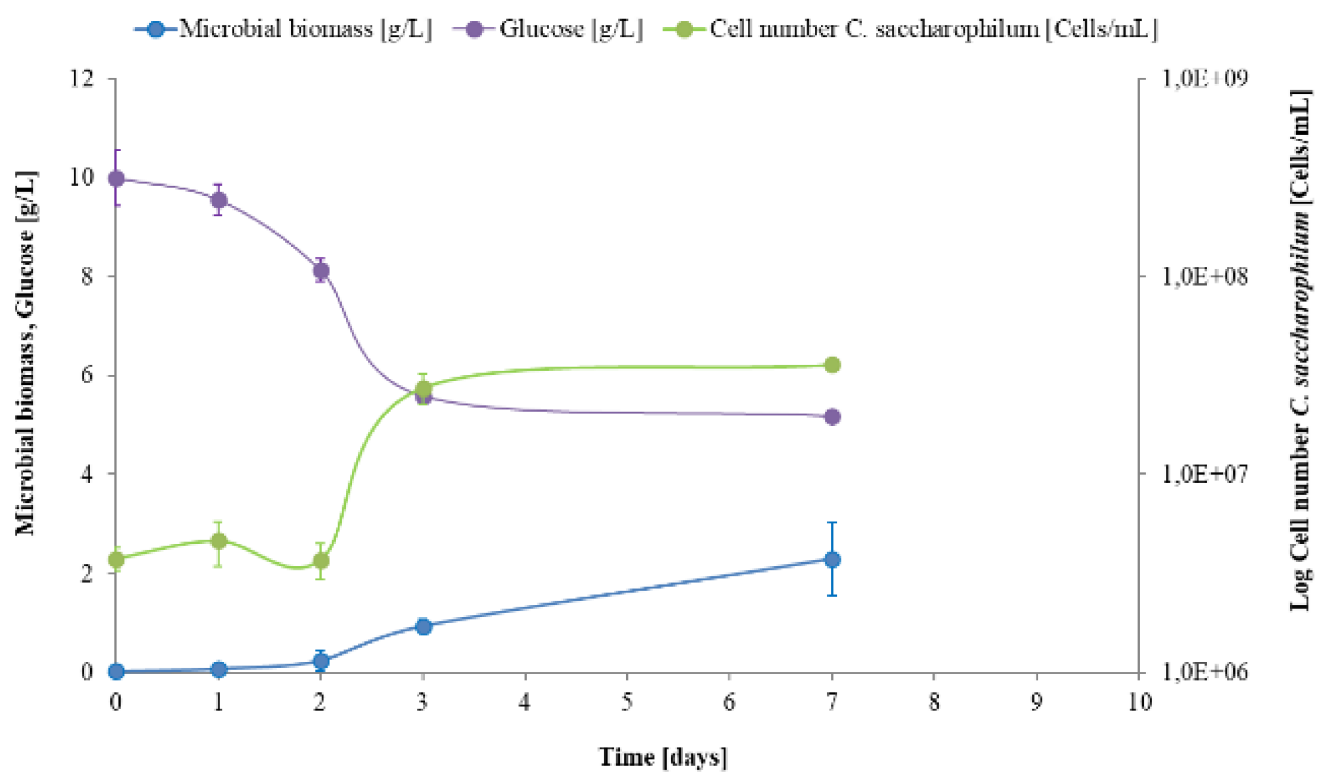

(a)

Figure 1. Cont. 


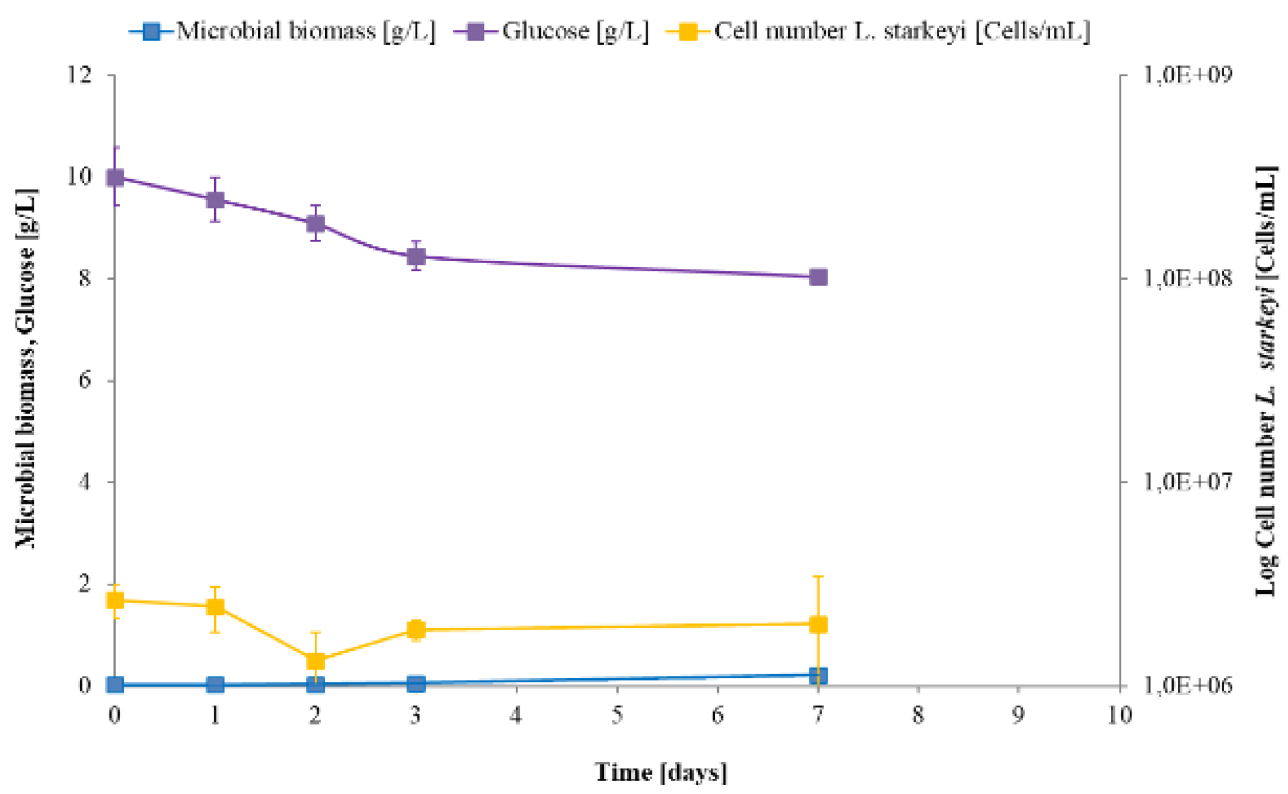

(b)

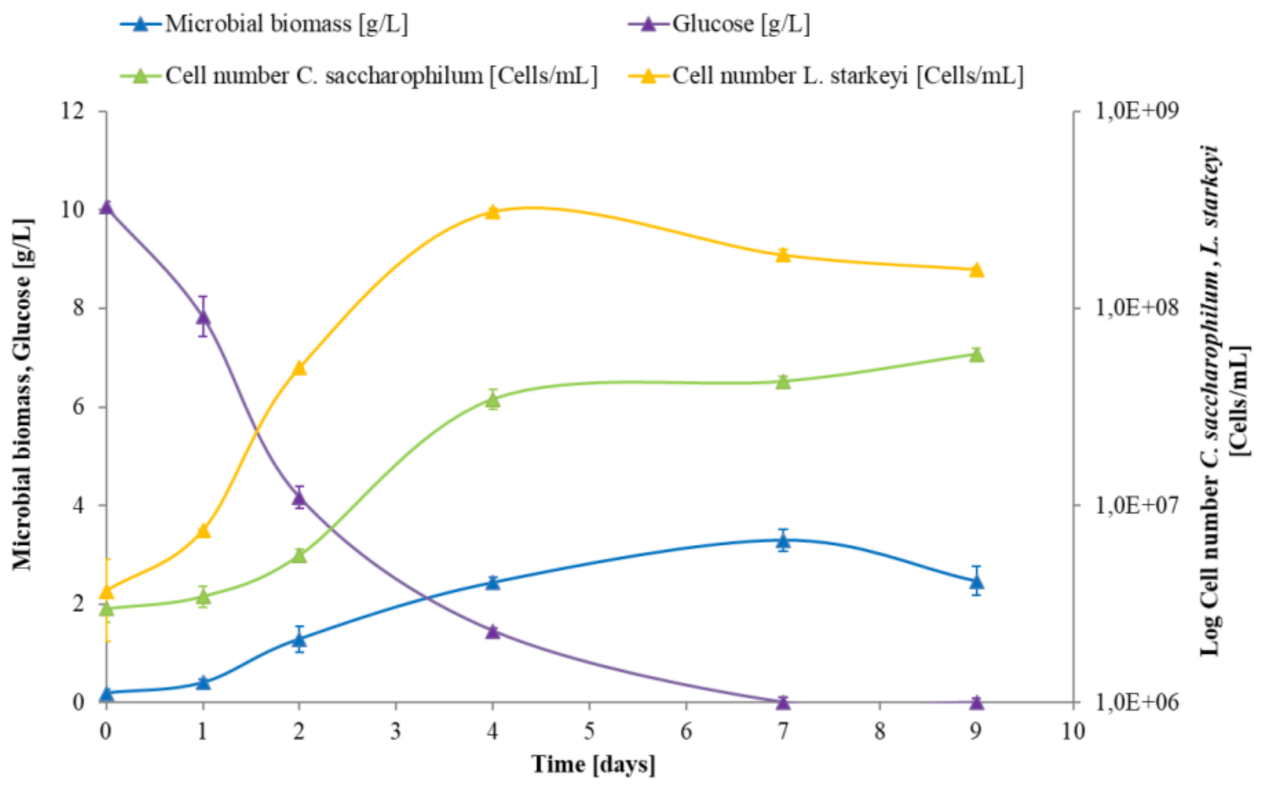

(c)

Figure 1. (a,b) Profiles of microbial biomass (g/L), glucose consumption $(\mathrm{g} / \mathrm{L})$ and cell number (cells $/ \mathrm{mL}$ ) in BBM + G medium supplemented with yeast extract and glucose inoculated by $\mathrm{C}$. saccharophilum (a) and L. starkeyi (b). (c) Profiles of microbial biomass (g/L), glucose consumption (g/L) and cell number (cells $/ \mathrm{mL}$ ) in BBM $+\mathrm{G}$ medium supplemented with yeast extract and glucose inoculated by C. saccharophilum and L. starkeyi in mixed culture. 


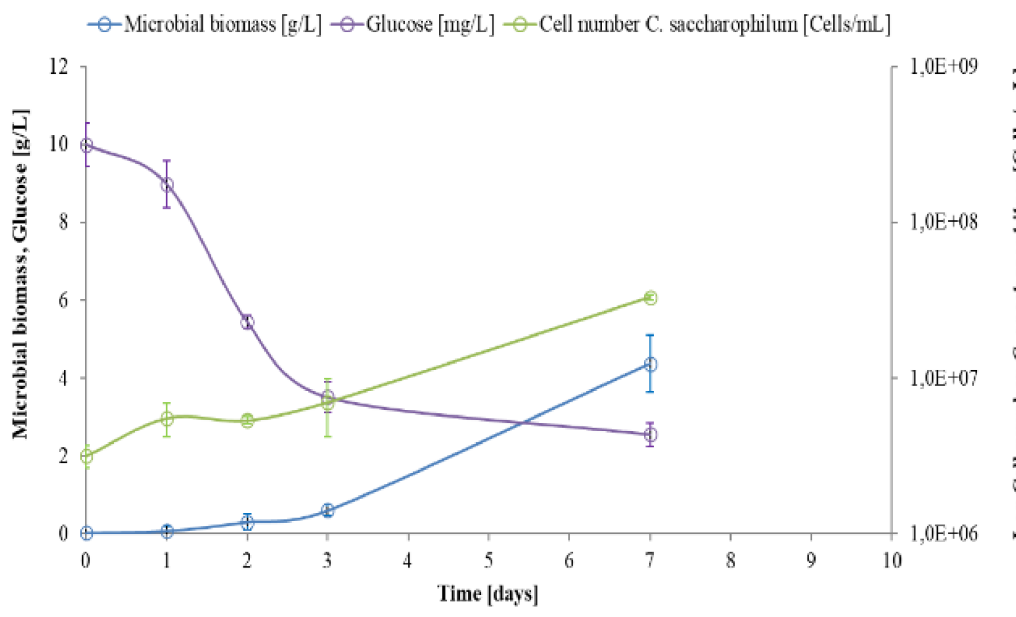

(a)

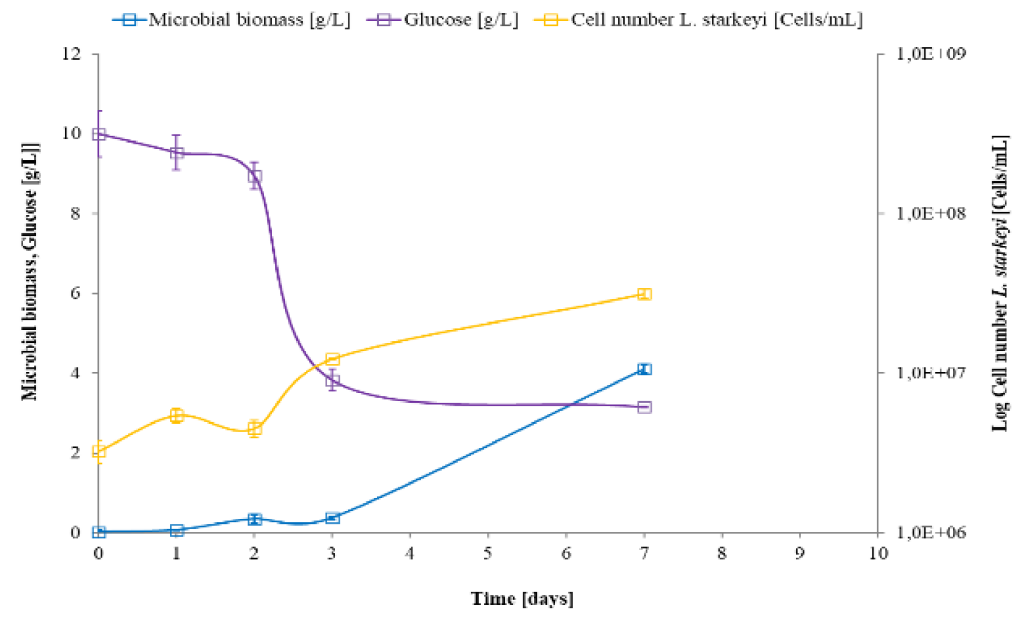

(b)

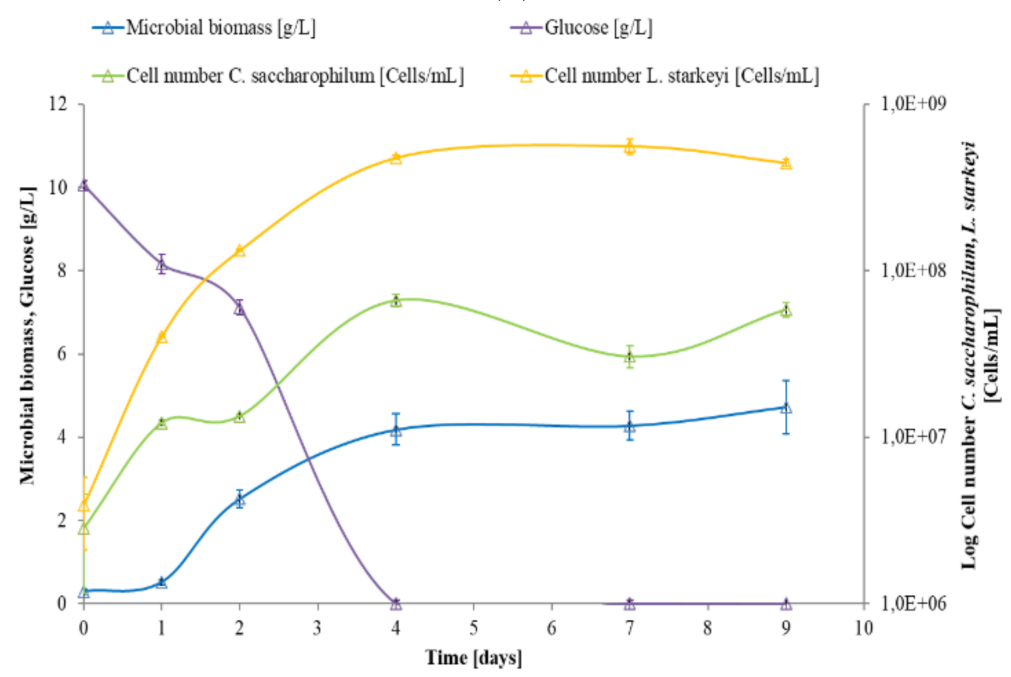

(c)

Figure 2. (a,b) Profiles of microbial biomass ( $\mathrm{g} / \mathrm{L})$, glucose consumption $(\mathrm{g} / \mathrm{L})$ and cell number (cells $/ \mathrm{mL}$ ) in YEG medium inoculated by C. saccharophilum (a) and L. starkeyi (b). (c) Profiles of microbial biomass $(\mathrm{g} / \mathrm{L})$, glucose consumption $(\mathrm{g} / \mathrm{L})$ and cell number (cells/mL) in YEG medium inoculated by C. saccharophilum and L. starkeyi in mixed culture. 
Table 1. Growth characteristics of the mixed cultures and the strains alone in BBM $+\mathrm{G}, \mathrm{YEG}$ media and Arundo donax hydrolysates. Data shown as mean \pm SD, $n=3$.

\begin{tabular}{|c|c|c|c|c|c|c|c|c|c|c|c|c|c|}
\hline Sample & $\begin{array}{c}\mu_{x} \\
{\left[\mathrm{~d}^{-1}\right]}\end{array}$ & $\begin{array}{c}Y_{x / s} \\
{\left[\mathbf{g} \cdot \mathbf{g}^{-1}\right]}\end{array}$ & $\begin{array}{c}\mu_{s} \\
{\left[d^{-1}\right]}\end{array}$ & $\begin{array}{c}P_{\mathrm{CO} 2} \\
{\left[\mathrm{mg} \cdot \mathbf{L}^{-1} \cdot \mathbf{d}^{-1}\right]}\end{array}$ & $\underset{\text { Lipid [g] }}{\mathbf{m}}$ & $\begin{array}{c}\text { Lipid } \\
\text { Content } \\
\left.\text { [g }_{\text {lipid. }} \text {. }_{\text {biomass }}{ }^{-1}\right]\end{array}$ & $\begin{array}{c}\text { Lipid Yield } \\
\text { max Y Ylipid max } \\
{\left[\mathbf{g g}_{\left.\mathbf{L}^{-1}\right]}\right.}\end{array}$ & 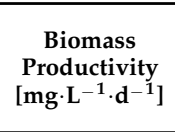 & 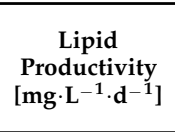 & $\begin{array}{c}\text { Cells }_{\max } \\
\text { C. saccharophila } \\
{\left[10^{6} \text { cells } \cdot \mathrm{mL}^{-1}\right]}\end{array}$ & $\begin{array}{c}\text { Cells }_{\max } \\
\text { L. starkeyi } \\
{\left[10^{6} \text { cells } \cdot \mathrm{mL}^{-1}\right]}\end{array}$ & $\begin{array}{c}\text { Lipid Yield } \\
\text { max/Cell max } \\
\text { C. saccharophila } \\
{\left[\mu \mathrm{g} \cdot \text { cells }^{-1} \cdot 10^{-6}\right]}\end{array}$ & $\begin{array}{c}\text { Lipid Yield } \\
\text { max/Cell max } \\
L . \text { starkeyi } \\
{\left[\mu \mathrm{g} \cdot \text { cells }^{-1} \cdot 10^{-6}\right]}\end{array}$ \\
\hline $\mathrm{BBM}+\mathrm{G}$ Chl & 0.381 & 0.471 & 0.689 & 610.0 & 0.018 & $0.076 \pm 0.03$ & $0.175 \pm 0.04$ & 328.57 & 25.00 & $36.0 \pm 1.76$ & & 4.9 & \\
\hline BBM + G Lip & 0.037 & 0.095 & 0.279 & 49.9 & 0.002 & $0.093 \pm 0.01$ & $0.020 \pm 0.04$ & 30.65 & 2.87 & & $2.0 \pm 0.65$ & & 10.0 \\
\hline BBM + G Chl Lip & 0.472 & 0.308 & 1.437 & 474.7 & 0.021 & $0.064 \pm 0.02$ & $0.211 \pm 0.17$ & 366.20 & 30.14 & $58.7 \pm 1.93$ & $309.3 \pm 5.91$ & 3.6 & 0.7 \\
\hline YEG Chl & 0.944 & 0.583 & 1.065 & 1168.6 & 0.022 & $0.051 \pm 0.01$ & $0.221 \pm 0.24$ & 625.00 & 31.57 & $33.0 \pm 1.27$ & & 1.5 & \\
\hline YEP Lip & 0.803 & 0.596 & 0.978 & 1095.9 & 0.021 & $0.052 \pm 0.03$ & $0.212 \pm 0.07$ & 586.31 & 30.29 & & $31.5 \pm 0.77$ & & 6.7 \\
\hline YEG Chl Lip & 1.166 & 0.440 & 1.118 & 925.4 & 0.032 & $0.068 \pm 0.01$ & $0.32 \pm 0.28$ & 611.90 & 35.56 & $66.7 \pm 3.21$ & $561.3 \pm 16.64$ & 1.0 & 0.1 \\
\hline ADH Chl & 0.003 & $0.000 *$ & 0.065 & 3.8 & 0.002 & $0.069 \pm 0.03$ & $0.016 \pm 0.00$ & 26.75 & 1.86 & $3.2 \pm 0.37$ & & 5.0 & \\
\hline ADH Lip & 0.614 & $0.422 *$ & 0.883 & 837.2 & 0.032 & $0.074 \pm 0.01$ & $0.318 \pm 0.05$ & 552.38 & 35.33 & & $32.45 \pm 1.87$ & & 9.8 \\
\hline ADH Chl Lip & 0.791 & 0.539 * & 0.786 & 822.2 & 0.034 & $0.081 \pm 0.04$ & $0.335 \pm 0.14$ & 365.47 & 37.22 & $20.9 \pm 1.23$ & $110.0 \pm 3.83$ & 16.0 & 3.0 \\
\hline
\end{tabular}

* Yield factor, $Y_{x / s}$, was calculated taking in account the contribute of all the monitored substrates. 
Similar biomass profiles were observed in the presence of $C$. saccharophilum and L. starkeyi alone, when simultaneously no substrate inhibition was observed as shown by the corresponding glucose consumption profile (Figure 2a,b). The cessation of glucose consumption was rather attributed to the progressive consumption of $\mathrm{CO}_{2}$ and $\mathrm{O}_{2}$ for C. saccharophilum alone (Figure 2a) and L. starkeyi alone (Figure 2b), respectively. Moreover, this inhibition is due to a probable $\mathrm{N}$ source limitation. On the other hand, where the growth inhibition was observed (Figure 1b), the corresponding glucose consumption was lower. In the presence of co-cultures (Figures $1 \mathrm{c}, 2 \mathrm{c}$ and $3 \mathrm{c}$ ), the virtuous loop $\mathrm{CO}_{2}-\mathrm{O}_{2}$ helped glucose consumption, but the progressive imbalance in the $\mathrm{C} / \mathrm{N}$ ratio is also a form of inhibition that prevents a proportional increase in the concentration of microbial biomass. On the contrary, microalgae growth would be inhibited, due to excessive nutrient consumption caused by a high yeast:microalga ratio [33].

The individual cultures of C. saccharophilum (Figure 2a) and L. starkeyi (Figure 2b) show similar trends, as also confirmed by the values of specific growth rate $\left(\mu_{x}\right)$ equal to 0.94 and $0.8 \mathrm{~d}^{-1}$, respectively, and the maximum value of cell concentration (cells. $\mathrm{mL}^{-1}$ ) which for the alga was equal to $3.3 \times 10^{7}$ and for the yeast to $3.1 \times 10^{7}$. Mixotrophic activity of $C$. saccharophilum seemed to be confirmed by glucose consumption profile (Figure 2a). Instead, L. starkeyi alone showed an initial lag phase (Figure 2b). Therefore, although initially there were no limiting conditions with regard to oxygen concentration, the yeast needed an evident acclimation phase in terms of microbial biomass rather than the profile associated to the number of cells (cells $\mathrm{mL}^{-1}$ ), which increased with linear trend from the beginning (Figure 2b). Once the oxygen became limiting, i.e., after the third day, as observed also by the absence of further substrate consumption able to affect $\mathrm{C} / \mathrm{N}$ ratio and consequently cell duplication, L. starkeyi showed a shift in metabolic activity directed on lipid accumulation. The effect of this metabolic turnover could be explained by the significant increase in microbial biomass, related to the occurrence of lipid bodies within the cell. Concerning C. saccharophilum alone, an initial phase of mixotrophic metabolism was followed by an autotrophic final phase, visible from the interruption of glucose assimilation. This was also done for the alga; therefore, during the final phase of the test, a lipid accumulation seems to be present, but it was related to a significant increase in the cell concentration due to the autotrophic metabolism. When C. saccharophilum and L. starkeyi were grown in mixed culture of YEG medium (Figure 2c), a synergistic effect was observed, confirming the results obtained with the enriched BBM $+G$ medium. Therefore, the mixotrophic metabolism of the microalga and the yeast fermentation were not in competition for the organic $\mathrm{C}$ source or $\mathrm{N}$ and $\mathrm{P}$, but rather they benefited from each other's metabolic activity, i.e., the consequent presence of a $\mathrm{O}_{2}-\mathrm{CO}_{2}$ virtuous loop. This seems evident looking at the initial glucose consumption rate in the case of L. starkeyi alone (Figure 2b) and L. starkeyi and C. saccharophilum mixed culture (Figure 2c). The presence of $\mathrm{O}_{2}$ overproduction by the microalgal metabolism supported the fermentation and therefore the consumption of the organic substrate. If the specific growth rate $\left(\mu_{x}\right)$ (Table 1) was positively influenced by the mixed culture, different was the case related to the yield factor $\left(Y_{x / s}\right)$, since the need of microbial biomass for organic carbon conversion increased as consequence of higher cell concentration in the inoculum. In fact, it changed from $0.583 \mathrm{~g} \cdot \mathrm{g}^{-1}$ for C. saccharophilum alone to $0.596 \mathrm{~g} \cdot \mathrm{g}^{-1}$ for L. starkeyi alone and $0.44 \mathrm{~g} \cdot \mathrm{g}^{-1}$ for mixed culture. The choice of a 1:1 ratio of microalga:yeast was made in relation to what was observed in a previous study [31] and according to what was highlighted, for example, by Ling et al. [34] and Li et al. [33]. An imbalance in the microalga:yeast inoculum ratio generally motivated by their different growth rates, besides not inducing a net increase in terms of lipid productivity, can sometimes lead to an accentuation for $\mathrm{N}$ and $\mathrm{P}$ competition, and consequently to an imbalance in $\mathrm{pH}$. Figure $2 \mathrm{c}$ also shows that, once the carbon source was depleted, the consequence was, also in this case, the stopping of cell proliferation, as shown by the unmodified cell concentration. 


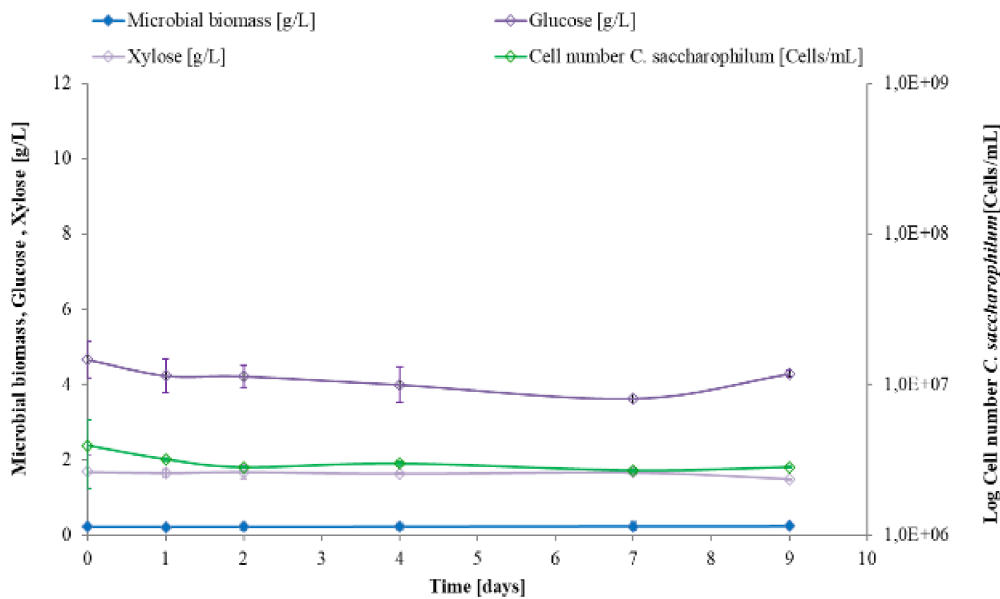

(a)
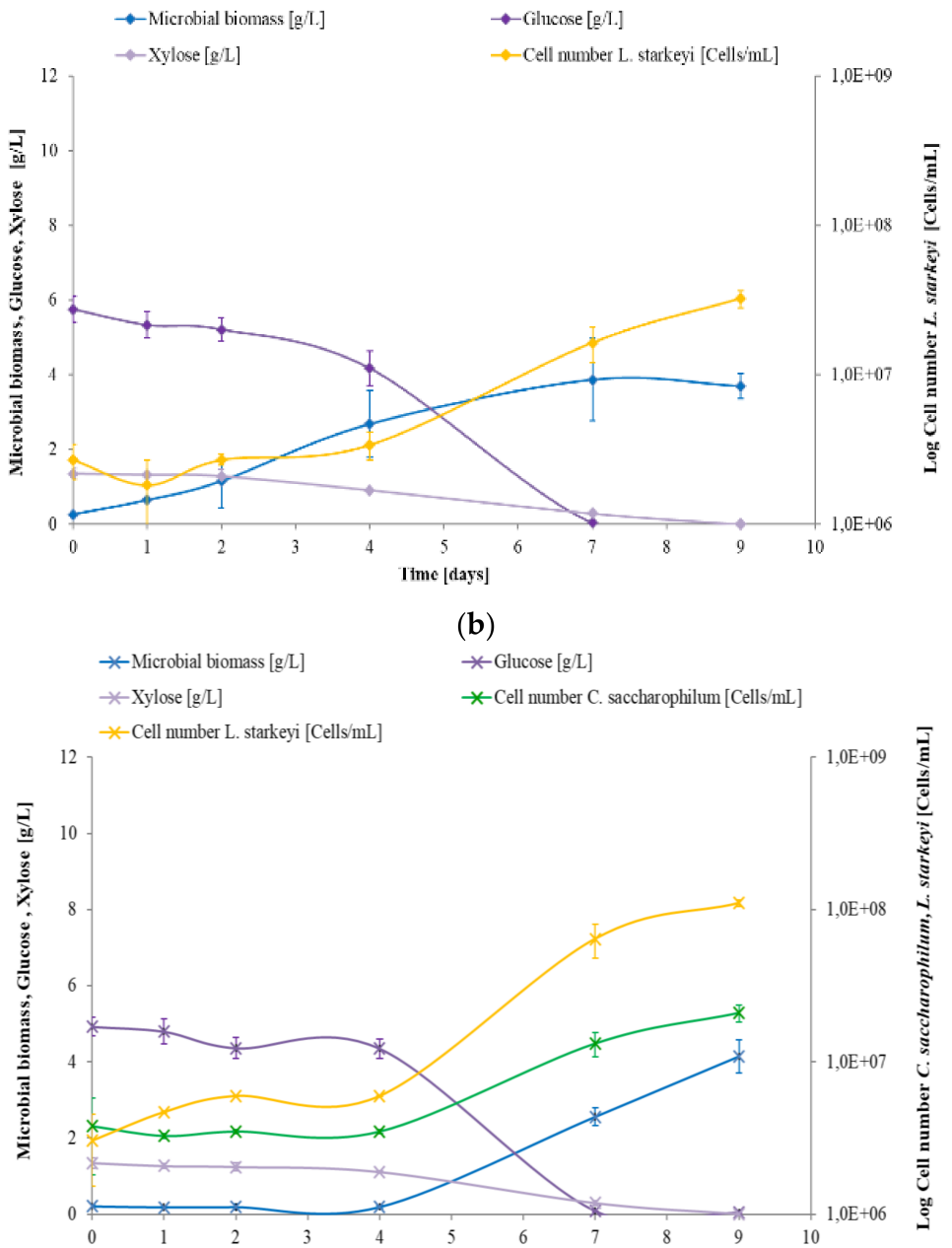

(c)

Figure 3. (a,b) Profiles of microbial biomass (g/L), glucose consumption (g/L), xylose consumption (g/L) and cell number (cells/mL) in Arundo donax hydrolysate (ADH) inoculated by C. saccharophilum (a) and L. starkeyi (b). (c) Profiles of microbial biomass (g/L), glucose consumption (g/L), xylose consumption $(\mathrm{g} / \mathrm{L}$ ) and cell number (cells $/ \mathrm{mL}$ ) in Arundo donax hydrolysate (ADH) inoculated by C. saccharophilum and L. starkeyi in mixed culture. 


\subsection{Study of C. saccharophilum and L. starkeyi Single and Mixed Cultures in Arundo donax Hydrolysate}

The performances in synthetic media described in the previous paragraph were considered necessary before moving to a real system, represented by the hydrolysate, in which the performance of the alga and yeast was evaluated individually and then in a mixed culture. Arundo donax was previously subjected to steam explosion and enzymatic hydrolysis. These two preliminary processes were chosen considering evaluations supported by experimental campaigns previously performed and aimed to optimize the operating conditions, minimize the release of inhibiting compounds and maximize the concentration of fermentable sugars. The steam explosion represents a pre-treatment able to facilitate the access of the crystalline structure of lignocellulosic biomass to hydrolytic enzymes and to limit the negative effects just discussed. Enzymatic hydrolysis was chosen for its operating conditions, which remain less impacting compared to other hydrolytic processes, further reducing the risk to increase the production and the release of inhibitory compounds [35]. As observed in Figure 3a, C. saccharophilum alone did not present any form of microbial growth that could be associated to the presence of inhibitory compounds. The choice of C. saccharophilum was made also in view of its high tolerance to the presence, for example, of phenols, recognizing in these latter compounds also a positive effect on the regulation of enzymatic activity, cell membrane structure and macromolecule synthesis [36-38]. Furans could also be a reason for inhibition since they are able to cause long lag-phase [39]. Therefore, the permanence of this regime led to the exhaustion of $\mathrm{CO}_{2}$ and subsequently of $\mathrm{O}_{2}$ source, making the culture substantially anaerobic and therefore unable to grow. A further aspect preliminarily considered was the possible inhibition due to the turbidity of the culture medium that in other studies led to adopting a dilution factor to promote photosynthetic activity [40] involving, at the same time, a loss in organic substrates concentration. On the other hand, the inhibition could be attributed to acetate potentially present in the dissociated form at neutral $\mathrm{pH}$, as in our case [41]. Russel [42] attributed the inhibitory effects of weak acids to two mechanisms: uncoupling and intracellular anion accumulation. For all these reasons, i.e., associated to the possible occurrence of limiting conditions in terms of $\mathrm{CO}_{2}$ or $\mathrm{O}_{2}$ and the potential inhibiting aspects such as turbidity or too high concentration in acetate, the study of mixed culture was found to be fundamental and potentially able to answer the doubts resulting from the single culture of $C$. saccharophilum. Another not secondary aspect that could have been the cause of algae inhibition is $\mathrm{C} / \mathrm{N}$ ratio. In fact, the use of low-cost feedstock, which is motivated by the need to reduce the costs of the growth medium and the positive effect on the increase of lipid accumulation, presents, however, a high $\mathrm{C} / \mathrm{N}$ ratio that exceeds the optimal values for the algae.

Before arriving at the mixed culture analysis, an additional control culture was monitored considering L. starkeyi alone as inoculum. Figures $3 \mathrm{~b}$ and $4 \mathrm{~b}$ show the relative trends in terms of metabolites (substrates and products) and microbial biomass. The lag phase associated to the first two days seemed caused by the presence of furans, which, although not in high concentration, represented a compound able to delay the growth phase. The hypothesis that the yeast inhibition is affected by the $\mathrm{C} / \mathrm{N}$ ratio was ruled out, given its ability to tolerate values of even 100 [4]. The lag phase was therefore followed by a growth phase, more visible in terms of microbial biomass than in terms of cells $\cdot \mathrm{mL}^{-1}$, which was the result of the simultaneous assimilation of glucose, xylose and acetate. This aspect confirmed what was observed by Anschau et al. [43], Gong et al. [44] and Yang et al. [45] related to the potential use of this microorganism in the presence of more complex feedstocks where co-metabolism is of great interest to solve inhibition problems due to volatile organic acids formed during the pretreatments and it should be valuable towards conversion of acetate lignocellulosic biomass materials into SCOs. Moreover, acetate assimilation by L. starkeyi represents a positive aspect with respect to $\mathrm{pH}$ adjustment, but it leads to an additional demand for dissolved oxygen. 


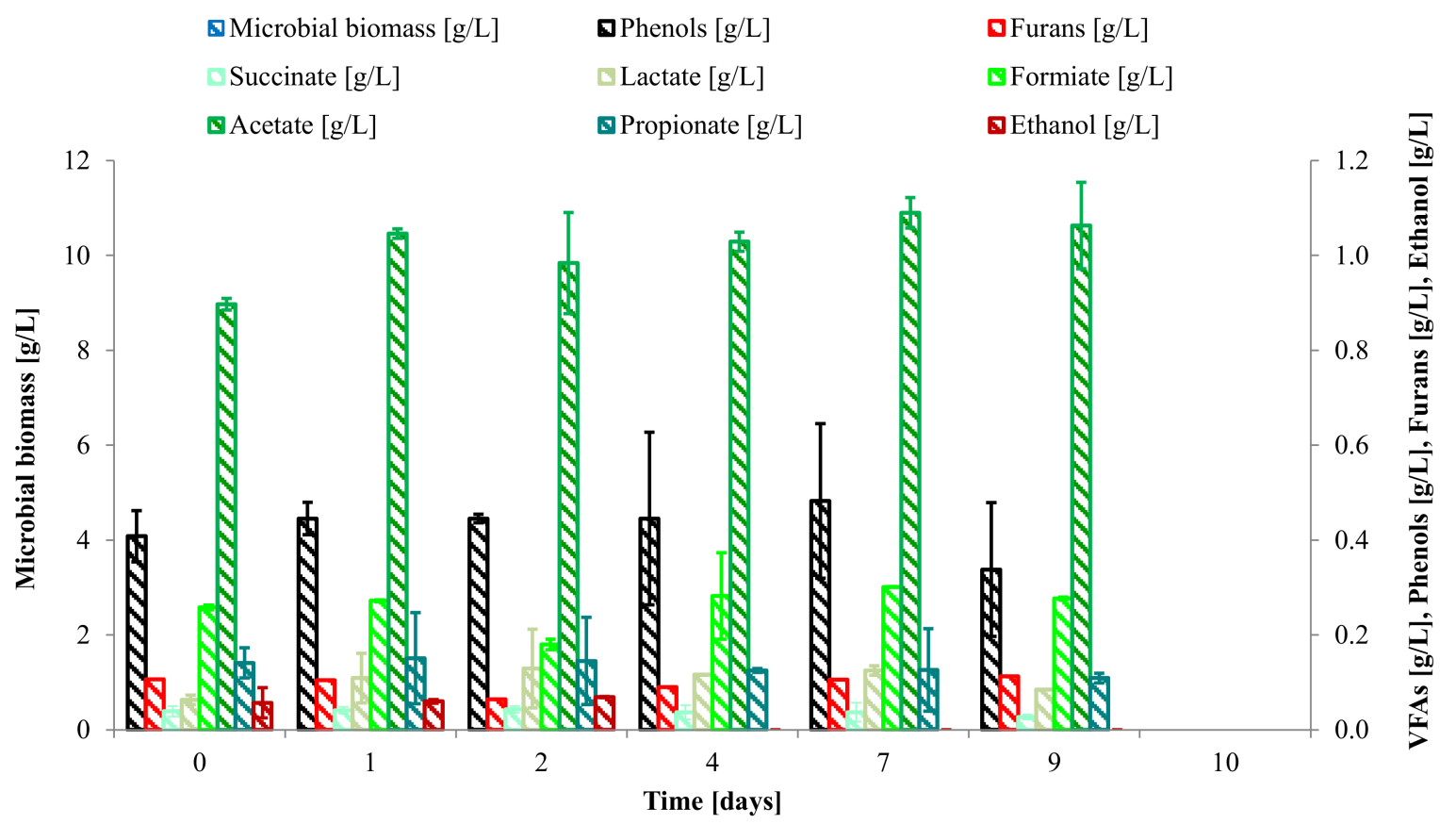

(a)

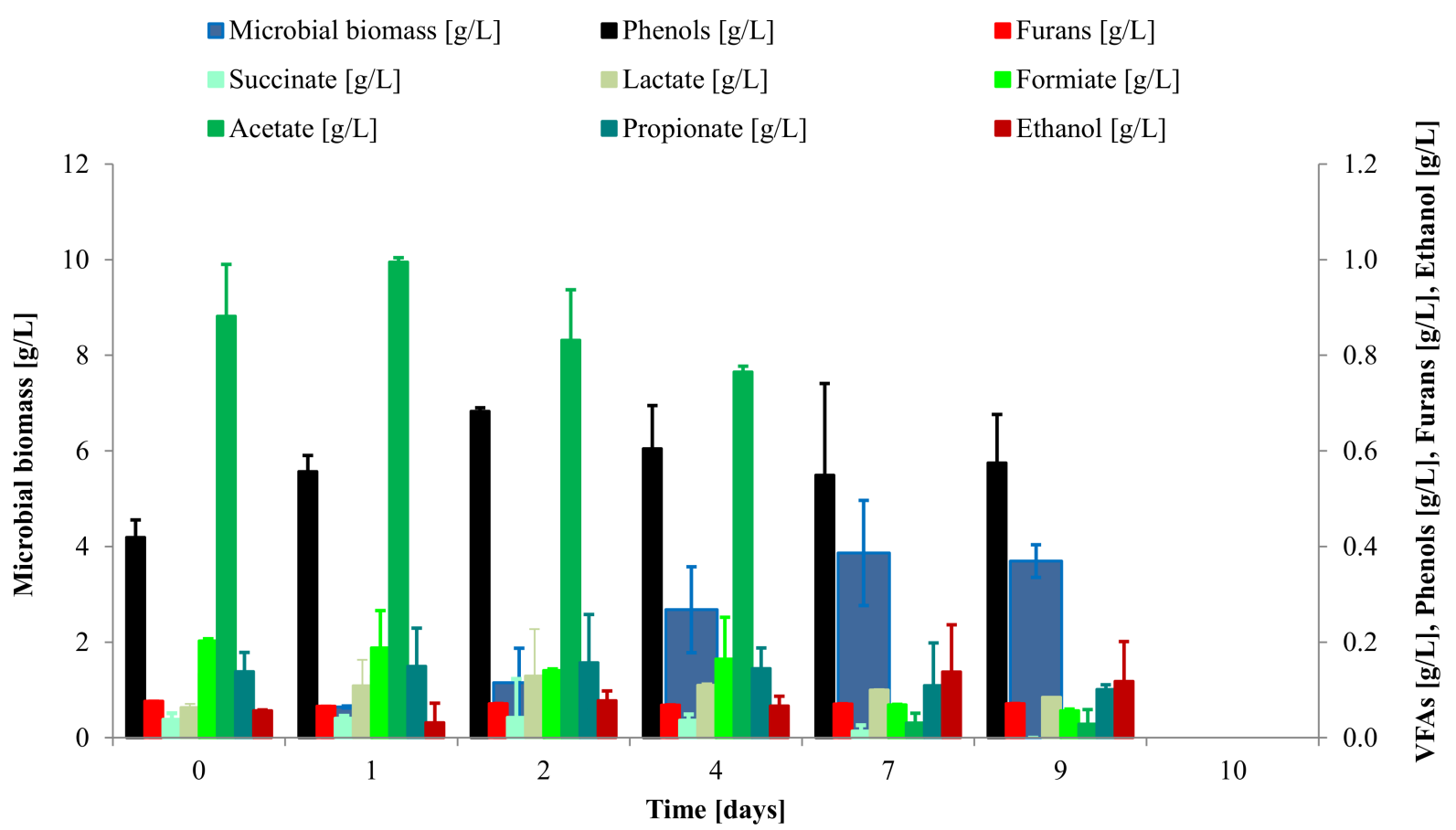

(b)

Figure 4. Cont. 


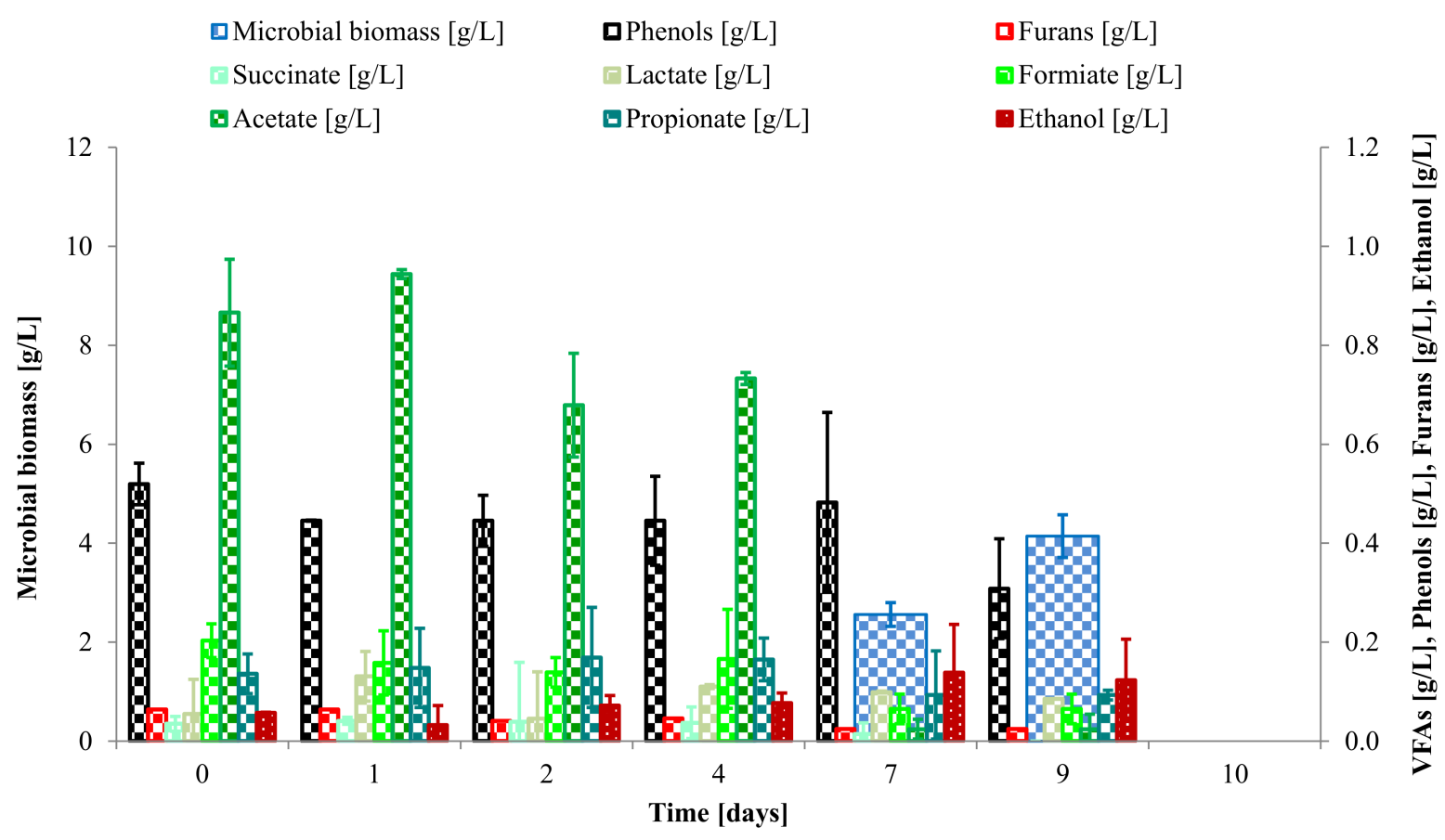

(c)

Figure 4. (a) Profiles of microbial biomass (g/L), VFAs, Phenols and Furans concentration (g/L) in Arundo donax hydrolysate (ADH) inoculated by C. saccharophilum. (b) Profiles of microbial biomass (g/L), VFAs, Phenols and Furans concentration (g/L) in Arundo donax hydrolysate (ADH) inoculated by L. starkeyi. (c) Profiles of microbial biomass (g/L), VFAs, Phenols and Furans concentration (g/L) in Arundo donax hydrolysate (ADH) inoculated by C. saccharophilum and L. starkeyi.

Figures $3 \mathrm{~b}$ and $4 \mathrm{~b}$ show how the consumption patterns of the substrates, i.e., mainly glucose, xylose and acetate, followed a diauxic mechanism. The consumption pattern of substrates is consistent with the metabolism becoming fermentative. The concentration and productivity of microbial biomass (Table 1 ) were $3.7 \mathrm{~g} \cdot \mathrm{L}^{-1}$ and $411 \mathrm{mg} \cdot \mathrm{L}^{-1} \cdot$ day $^{-1}$, respectively. These values can be considered in line with those obtained by Pirozzi et al. [46] considering that Arundo donax was submitted to different pre-treatment processes, but different by one order of magnitude when compared to hydrolysates of wheat corn, corn bran and corn stover $[15,47,48]$.

Finally, Arundo donax hydrolysate was inoculated with a mixed culture of L. starkeyi and C. saccharophilum to observe the positive and less positive effects of the two-microorganism combination also in relation to what was previously studied with regard to synthetic media in which all aspects due to inhibitory effects resulting from the complexity of the hydrolysate were missing. Meanwhile, as shown in Figure 3c, the lag phase lasted for the first four days, apart from a slight increase in L. starkeyi cell number that passed from $3.3 \times 10^{6}$ to $5.9 \times 10^{6}$ cells. $\mathrm{mL}^{-1}$, mainly as a result of glucose consumption rate, equal to $0.28 \mathrm{~g} \cdot \mathrm{L}^{-1} \cdot \mathrm{day}^{-1}$. At this stage, inhibition due to the presence of inhibiting compounds, such as furans and phenols was confirmed, but once the lag phase was exceeded both microorganisms showed a growth capacity that, in the case of C. saccharophilum, was not observed in single culture. The max values of cells $\mathrm{mL}^{-1}$ for L. starkeyi and C. saccharophilum in mixed culture were $1.1 \times 10^{8}$ and $2.1 \times 10^{7}$, respectively. These values were understandably lower than those found for mixed culture in YEG medium, respectively, equal to $5.6 \times 10^{8}$ and $6.7 \times 10^{7}$ cells $\cdot \mathrm{mL}^{-1}$, because of faster glucose consumption and absence of inhibition phenomena.

What seemed evident, confirming what has been observed in previous studies [31,32,49-51], was the presence of a synergistic effect that in our case was attributed to different processes. During the lag phase, L. starkeyi showed a latent growth phase 
(Figure 3c) that induced a progressive endogenous source of $\mathrm{CO}_{2}$ able to avoid limiting conditions for the microalga growth. As observed in the single culture (Figure 3a), the microalga did not grow according to a heterotrophic metabolism or mixotrophic because of the various forms of inhibition just discussed. This progressive accumulation of $\mathrm{CO}_{2}$, not to the point of representing a form of inhibition for the yeast, could be the cause of a partial acidification of the culture medium, but both C. saccharophilum and L. starkeyi tolerate acid $\mathrm{pH}$. This acidification was therefore counteracted by acetate consumption after the fourth day, since a $\mathrm{pH}$ increase is typically observed when a microorganism grows in a salt of an organic acid. The progressive consumption of the organic substrate, and thus the decrease in the $\mathrm{C} / \mathrm{N}$ ratio that was crucial for the inhibition of single microalgae growth, together with the $\mathrm{pH}$ control due to acetate consumption to balance the potential acidification due to yeast respiration, were the positive aspects that favored the symbiotic growth of $C$. saccharophilum in mixed culture. In terms of the final microbial biomass, the differences were not evident when passing from 4.72 to $4.14 \mathrm{~g} \cdot \mathrm{L}^{-1}$ for mixed cultures in YEG medium and in Arundo donax hydrolysate (Figures $2 c$ and 3c), this was different when evaluated in terms of microbial biomass productivity measured in the same time-range, equal, respectively, to 611.9 and $365.5 \mathrm{mg} \cdot \mathrm{L}^{-1} / \mathrm{day}^{-1}$, showing in the latter case the incidence of inhibiting phenomena that slowed down the growth phase. The microbial biomass growth rate $\left(\mu_{x}\right)$ and the yield factor $\left(Y_{x / s}\right)$ in mixed culture were, respectively, 0.791 day $^{-1}$ and $0.539 \mathrm{~g} \cdot \mathrm{g}^{-1}$ (Table 1$)$. Once this synergistic effect stopped as a consequence of limiting conditions achievement in terms of $\mathrm{O}_{2}$, yeast growth rate changed, switching to a fermentative metabolism and consequently to ethanol accumulation, negatively influencing also the alga, whose growth also suffered a slowdown (Figure 3c).

Studies about the tolerance of single microbe species to inhibitory compounds are quite limited. Several attempts have been made to promote the microbial growth by reducing toxic compounds before fermentation process with certain detoxification steps. However, the detoxification which directly leads to high cost will decrease the economy of the whole process [52]. The fact that depletions of hydrolysis degradation products were enhanced by the mixed culture mode should be regarded positively because the overall process of microbial lipid production from lignocellulosic hydrolysate can be simplified by omitting the need of a detoxification step [49].

\subsection{Lipid Production and Fatty Acid Distribution}

Different parameters were evaluated, as reported in Table 1, to compare the incidence of the culture conditions adopted onto the lipid content, lipid yield and lipid productivity. Nutrient limitation, notoriously an imbalance of $\mathrm{C} / \mathrm{N}$ ratio, promotes lipogenesis. However, other factors besides nitrogen-limitation could induce lipogenesis in oleaginous yeasts, including the effect of phosphate and sulfur limitation. Indeed, soluble phosphates could be precipitated and removed by interaction with metal ions, such as $\mathrm{Ca}^{2+}$, $\mathrm{Mg}^{2+}$ or $\mathrm{Fe}^{3+}$, and the resulting hydrolysate, exhibiting high $\mathrm{C} / \mathrm{N}$ and $\mathrm{C} / \mathrm{P}$ ratio, could allow for even higher lipid accumulation [53]. The lipid content reached a maximum value of $0.081 \mathrm{~g}_{\text {lipid }} \cdot \mathrm{g}_{\text {biomass }}{ }^{-1}$ for mixed culture in Arundo donax hydrolysate, which was higher than the mixed culture in BBM + G or YEG, where the same value was about $0.063-0.064 \mathrm{~g}_{\text {lipid }} \cdot \mathrm{g}_{\text {biomass }}{ }^{-1}$. Therefore, these values were significantly lower to those obtained by Liu et al. [49], where the maximum lipid content was $0.53 \mathrm{~g}$ lipid $\cdot \mathrm{g}_{\text {biomass }}{ }^{-1}$ for Chlorella pyrenoidosa and Rhodotorula glutinis consortium. The explanation could be found in the differences in substrate concentration, which, in the latter case, amounted from $30-60 \mathrm{~g} \cdot \mathrm{L}^{-1}$ promoting consequently an imbalance in the $\mathrm{C} / \mathrm{N}$ ratio that could have favored microbial oil accumulation phase mainly by the yeast, whose metabolic activity is positively conditioned by the increase of this ratio [4]. The lipid yield values of mixed cultures in our study were $0.211 \mathrm{~g} \cdot \mathrm{L}^{-1}$ for BBM $+\mathrm{G}, 0.320 \mathrm{~g} \cdot \mathrm{L}^{-1}$ for YEG and $0.335 \mathrm{~g} \cdot \mathrm{L}^{-1}$ for Arundo donax hydrolysate. These values were very far from those measured by Liu et al. [49], where an average value of $7.73 \mathrm{~g} \cdot \mathrm{L}^{-1}$ was obtained; in line with those measured by Wang et al. [54] in the presence of C. pyrenoidosa and R. glutinis consortium, where the 
lipid yield was $0.75 \mathrm{~g} \cdot \mathrm{L}^{-1}$; and much higher than those of Iasimone et al. [54,55], where the lipid yield was $0.05 \mathrm{~g} \cdot \mathrm{L}^{-1}$ in the presence of a mixed culture of L. starkeyi and algae consortium mainly represented by Chlorella sp. and Scenedesmus sp.

Cell number normalized lipid contents (Lipid Yield/Cell) were also calculated (Table 1), obtaining values for $C$. saccharophilum and $L$. starkeyi mixed culture respectively equal to 16 and $3 \mu \mathrm{g}$ for $10^{-6}$ cells for Arundo donax hydrolysate. These values were comparable to those by Liu et al. [49] where for C. pyrenoidosa and R. glutinis were equal about to 16 and $14 \mu \mathrm{g}$ for $10^{-6}$ cells, respectively, indicating that the $\mathrm{C} / \mathrm{N}$ ratio of cassava bagasse hydrolysate probably enhanced the lipid accumulation metabolism of yeast rather than alga.

Fatty acid distribution was also monitored at the end of each culture, as shown in Figure 5a-c. Generally, the volumetric distribution in terms of C16:0, C16:1, C18:0, C18:1 and C18:2 for yeast monoculture was 7-20, $0.1-0.8,3-12,28-85$ and 5-20, while, for alga monoculture, it was $12-40,0.1-1,2-32,21-71$ and $0-10$. The effect of co-culture is a progressive increase in the concentration of saturated fatty acids (SFAs) and a reduction in polyunsaturated fatty acids (PUFAs) [4], which was previously observed by Zuccaro et al. [31] and partially confirmed in this study. Indeed, as described by Tkachenko et al. [56], at the intensification of aeration, the degree of lipid unsaturation and the relative amount of all groups of unsaturated acids increase. In fact, the compounds mainly present in our study were C18:0, C18:1 and C14:0, with an increasing concentration of C18:2 and C18:3 for single and mixed culture in Arundo donax hydrolysate. For the latter case, specifically, the distribution in terms of C14:0, C16:0, C18:0, C18:1, C18:2, C18:3 and C20:0 was the following: 7, 39, 30, 19, 2 and 0.1. In general, the lipids produced by microorganisms are converted into biodiesel via a process known as transesterification. The two most important properties of fatty acids that affect the fuel properties as listed above are: (a) the length of the carbon chain; and (b) the number of double bonds [57,58]. The degree of unsaturation in the fatty acids affects the oxidative stability of the biodiesel with SFAs being the most stable followed by MUFAs compared to the least stable PUFAs [59]. Additionally, C16:0 and C18:1 are used as food additives and cosmetics, indicating the SCOs from mixed culture using low-cost lignocellulosic feedstock such as Arundo donax could have several potential applications.

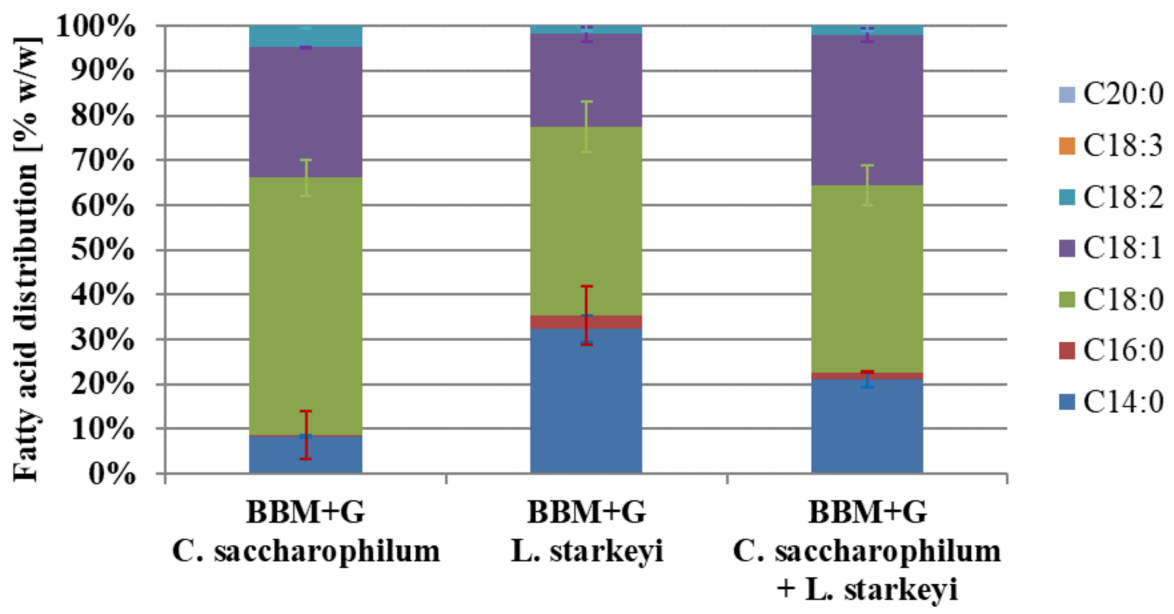

(a)

Figure 5. Cont. 


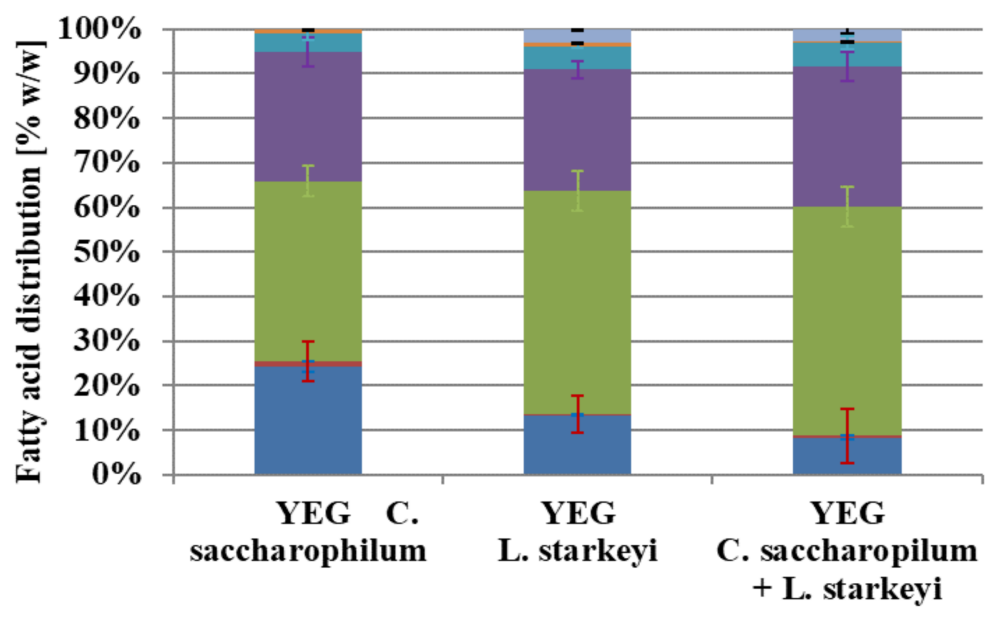

- $220: 0$

$\mathrm{C} 18: 3$

- $18: 2$

- $18: 1$

- $\mathrm{C} 18: 0$

- $\mathrm{C} 16: 0$

- $14: 0$

(b)

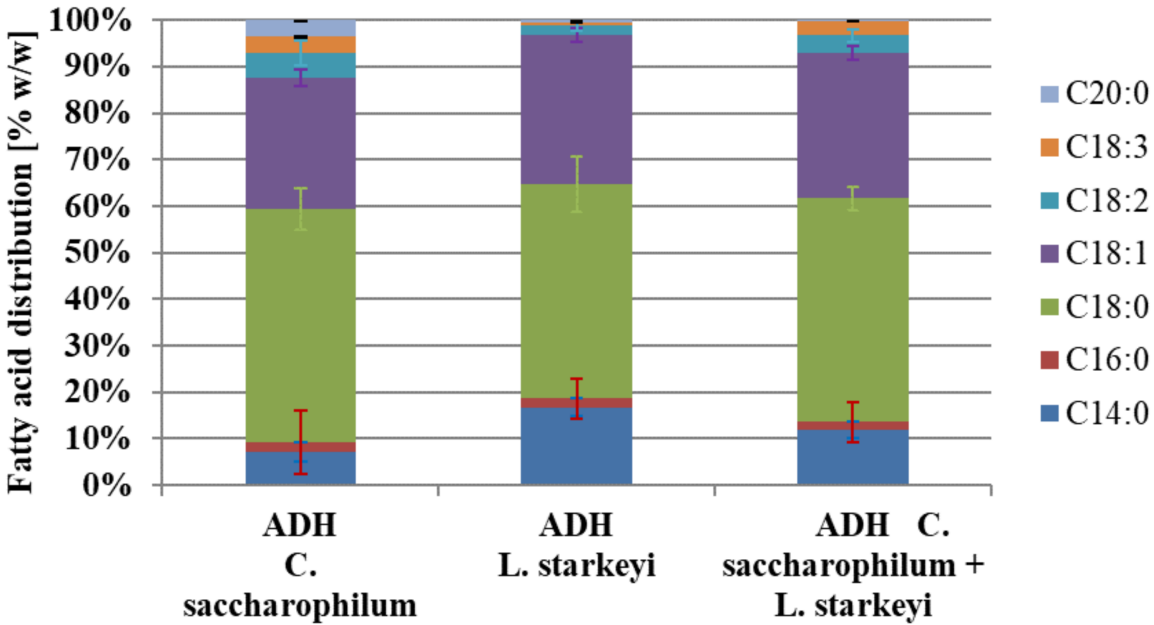

(c)

Figure 5. (a) Fatty acid distribution $(\% w / w)$ in microbial biomass (individual and mixed cultures) in $\mathrm{BBM}+\mathrm{G}$ media. (b) Fatty acid distribution $(\% w / w)$ in microbial biomass (individual and mixed cultures) in YEG media. (c) Fatty acid distribution ( $\% w / w)$ in microbial biomass (individual and mixed cultures) in ADH hydrolysates.

\section{Conclusions}

Lignocellulosic extracts have the potential to provide a complex substrate of fermentable sugars and volatile organic acids, mainly acetate, at low cost. In this study, it was shown that C. saccharophilum and L. starkeyi were able to grow according to a synergistic effect on complex substrate such as Arundo donax hydrolysate, while showing that this synergistic effect allowed overcoming the problems associated to inhibitory phenomena due to lignin or sugar degradation products and a non-optimal $\mathrm{C} / \mathrm{N}$ ratio. The reason was mainly attributed to the virtuous exchange of $\mathrm{O}_{2}$ and $\mathrm{CO}_{2}$, as well as to the phenomenon of $\mathrm{pH}$ regulation. The promising results in terms of microbial growth and lipid accumulation were correlated with those of cultures in less complex synthetic media. The mixed cultures, in all cases, proved to be the best performing. The operational and economic impacts associated with the introduction of a detoxification phase in an attempt to overcome the inhibition effects of the above-mentioned products remain to be clarified and deepened. SCO production from lignocellulosic biomass offers a new direction for bio-refinery approach, and it will have a great future if the above-mentioned problems are properly handled. In fact, SCOs represent intermediates for biodiesel production, polymers and biosurfactants, and the control of unsaturation degree in their chain, for example by hydrogenation, could be critical to ensure selectivity and stability. The exploitation of SCOs related to the possibil- 
ity of ensuring mono- or polyunsaturation could represent an alternative for the treatment of diseases such as atherosclerosis. Therefore, a decisive step in the direction of developing an economically sustainable method for the recovery of high purity SCOs is still awaited.

Author Contributions: A.d.M., G.P., A.P. and A.D.N.; formal analysis, G.Z. and A.d.M.; investigation, G.Z. and A.d.M.; resources, A.P. and A.D.N.; data curation, G.Z. and A.d.M.; writing-original draft preparation, G.Z.; writing—review and editing, G.Z., A.d.M., G.P., A.P. and A.D.N.; supervision, G.Z., A.P. and A.D.N.; project administration, A.D.N., funding acquisition, A.P. and A.D.N. All authors have read and agreed to the published version of the manuscript.

Funding: This research was funded by the project: FEAMP Campania 2014/2020-DRD n. 35 del 15.03.2019-Innovazione sviluppo sostenibilità settore pesca ed acquacoltura, WP4, misura 1.44.

Institutional Review Board Statement: Not applicable.

Informed Consent Statement: Not applicable.

Acknowledgments: G.Z. would like to thank ENEA-Trisaia Research Center (Rotondella, Matera, Italy). G.Z. gratefully acknowledges the Department of Chemical, Materials and Production Engineering (DICMaPI)—University of Naples Federico II for the support.

Conflicts of Interest: The authors declare no conflict of interest.

\section{References}

1. Pérez, A.T.E.; Camargo, M.; Rincón, P.C.N.; Marchant, M.A. Key challenges and requirements for sustainable and industrialized biorefinery supply chain design and management: A bibliographic analysis. Renew. Sustain. Energy Rev. 2017, 69, 350-359. [CrossRef]

2. Abghari, A.; Chen, S. Yarrowia lipolytica as an oleaginous cell factory platform for production of fatty acid-based biofuel and bioproducts. Front. Energy Res. 2014, 2, 1-21. [CrossRef]

3. Huang, C.; Chen, X.F.; Xiong, L.; Chen, X.D.; Ma, L.L.; Chen, Y. Single cell oil production from low-cost substrates: The possibility and potential of its industrialization. Biotechnol. Adv. 2013, 31, 129-139. [CrossRef] [PubMed]

4. Arora, N.; Patel, A.; Methani, J.; Pruthi, P.A.; Pruthi, V.; Poluri, K.M. Co-culturing of oleaginous microalgae and yeast: Paradigm shift towards enhanced lipid productivity. Environ. Sci. Pollut. Res. 2019, 26, 16952-16973. [CrossRef]

5. Naidoo, R.K.; Simpson, Z.F.; Oosthuizen, J.R.; Bauer, F.F. Nutrient exchange of carbon and nitrogen promotes the formation of stable mutualisms between Chlorella sorokiniana and Saccharomyces cerevisiae under engineered synthetic growth conditions. Front. Microbiol. 2019, 10, 609. [CrossRef]

6. Hays, S.G.; Yan, L.L.W.; Silver, P.A.; Ducat, D.C. Synthetic photosynthetic consortia define interactions leading to robustness and photoproduction. J. Biol. Eng. 2017, 11, 4. [CrossRef] [PubMed]

7. Li, T.; Li, C.T.; Butler, K.; Hays, S.G.; Guarnieri, M.T.; Oyler, G.A.; Betenbaugh, M.J. Mimicking lichens: Incorporation of yeasts strains together with sucrose secreting cyanobacteria improves survival, growth, ROS removal, and lipid production in a stable mutualistic co-culture production platform. Biotechnol. Biofuels 2017, 10, 55. [CrossRef]

8. Liu, J.; Huang, J.; Sun, Z.; Zhong, Y.; Jiang, Y.; Chen, F. Differential lipid and fatty acid profiles of photoautotrophic and heterotrophic Chlorella zofingiensis: Assessment of algal oils for biodiesel production. Bioresour. Technol. 2011, 102, 106-110. [CrossRef]

9. Wilhelm, C.; Jakob, T. From photons to biomass and biofuels: Evaluation of different strategies for the improvement of algal biotechnology based on comparative energy balances. Appl. Microbiol. Biotechnol. 2011, 92, 909-919. [CrossRef] [PubMed]

10. Chi, Z.; Zheng, Y.; Lucker, B.; Chen, S. Integrated System for Production of Biofuel Feedstock. U.S. Patent WO/2010/014797, 4 February 2010.

11. Beopoulos, A.; Nicaud, J.M. Yeast: A new oil producer? OCL 2012, 19, 22-28. [CrossRef]

12. Qin, L.; Liu, L.; Zeng, A.-P.; Wei, D. From low-cost substrates to Single Cell Oils synthesized by oleaginous yeasts. Bioresour. Technol. 2017, 245, 1507-1519. [CrossRef]

13. Lodder, J.; Kreger-van Rij, N.J.W. The Yeast: A Taxonomic Study, 1st ed.; North-Holland Publishing Company: Amsterdam, The Netherlands, 1952.

14. Darienko, T.; Gustavs, L.; Mudimu, O.; Menendez, C.R.; Schumann, R.; Karsten, U.; Friedl, T.; Proschold, T. Chloroidium, a common terrestrial coccoid green alga previously assigned to Chlorella (Trebouxiophyceae, Chlorophyta). Eur. J. Phycol. 2010, 45, 79-95. [CrossRef]

15. Calvey, C.H.; Su, Y.K.; Willis, L.B.; McGee, M.; Jeffries, T.W. Nitrogen limitation, oxygen limitation, and lipid accumulation in Lipomyces Starkeyi. Bioresour. Technol. 2016, 200, 780-788. [CrossRef]

16. McNeil, B.A.; Stuart, D.T. Optimization of C16 and C18 fatty alcohol production by an engineered strain of Lipomyces starkeyi. J. Ind. Microbiol. Biotechnol. 2018, 45, 1-14. [CrossRef] 
17. Xavier, M.C.A.; Coradini, A.L.V.; Deckmann, A.C.; Franco, T.T. Lipid production from hemicellulose hydrolysate and acetic acid by Lipomyces starkeyi and the ability of yeast to metabolize inhibitors. Biochem. Eng. J. 2017, 118, 11-19. [CrossRef]

18. Beardall, $\mathrm{J} . \mathrm{CO}_{2}$ accumulation by Chlorella saccharophilum (Chlorophyceae) at low external $\mathrm{pH}$ : Evidence for active transport of inorganic carbon at the chloroplast envelope. J. Phycol. 1981, 17, 371-373. [CrossRef]

19. Herrera-Valencia, V.A.; Contreras-Pool, P.Y.; Lopez-Adrian, S.J.; Peraza-Echeverria, S.; Barahona-Perez, L.F. The green microalga Chlorella saccharophilum as a suitable source of oil for biodiesel production. Curr. Microbiol. 2011, 63, 151-157. [CrossRef]

20. Tan, C.K.; Johns, M.R. Fatty acid production by heterotrophic Chlorella saccharophilum. Hydrobiologia 1991, 215, 13-19. [CrossRef]

21. Zhang, T.-Y.; Hu, H.-Y.; Wu, Y.-H.; Zhuang, L.-L.; Xu, X.-Q.; Wang, X.-X.; Dao, G.-H. Promising solutions to solve te bottlenecks in the large-scale cultivation of microalgae for biomass/bioenergy production. Renew. Sustain. Energy Rev. 2016, 60, 1602-1614. [CrossRef]

22. Fagnano, M.; Impagliazzo, A.; Mori, M.; Fiorentino, N. Agronomic and Environmental Impacts of Giant Reed (Arundo donax L.): Results from a Long-Term Field Experiment in Hilly Areas Subject to Soil Erosion. Bioenergy Res. 2015, 8, 415-422. [CrossRef]

23. Zuccaro, G.; Travaglini, G.; Caputo, G.; Pirozzi, D. Enzymatic Hydrolysis and Oleaginous Fermentation of Steam-Exploded Arundo donax and Lipomyces Starkeyi in a Single Bioreactor for Microbial Oil Accumulation. J. Multidiscip. Eng. Sci. Stud. 2019, 5, 2577-2586.

24. Garrote, G.; Domínguez, H.; Parajó, J.C. Hydrothermal processing of lignocellulosic materials. Holz Roh-Werkst 1999, 57, 191-202. [CrossRef]

25. Adney, B.; Baker, J. Measurement of Cellulase Activities; NREL Analytical Procedure LAP-006; National Renewable Energy Laboratory: Golden, CO, USA, 1996.

26. Wood, T.M.; Bhat, K.M. Methods for measuring cellulase activities. Methods Enzymol. 1988, 160, 87-112.

27. Singleton, V.L.; Orhofer, R.; Lamuela-Raventos, R.M. Analysis of total phenols and other oxidation substrates and antioxidants by means of Folin-Ciocalteau reagent. Methods Enzym. 1999, 299, 152-178.

28. Martinez, A.; Rodriguez, M.E.; York, S.W.; Preston, J.F.; Ingram, L.O. Use of UV absorbance to monitor furans in dilute acid hydrolysates of biomass. Biotechnol. Prog. 2000, 16, 637-641. [CrossRef]

29. Bligh, E.G.; Dyer, W.J. A rapid method of total lipid extraction and purification. Can. J. Biochem. Phys. 1959, 37, 911-917. [CrossRef] [PubMed]

30. Redfield, A.C. On the Proportions of Organic Derivatives in Sea Water and Their Relation to the Composition of Plankton. In James Johnstone Memorial Volume; University Press of Liverpool: Liverpool, UK, 1934; pp. 176-192.

31. Zuccaro, G.; Steyer, J.-P.; van Lis, R. The algal trophic mode affects the interaction and oil production of a synergistic microalgayeast consortium. Bioresour. Technol. 2019, 273, 608-617. [CrossRef] [PubMed]

32. Wijsman, M.R.; van Dijken, J.P.; van Kleeff, B.H.A.; Scheffers, W.A. Inhibition of fermentation and growth in batch cultures of the yeast Brettanomyces intermedius upon a shift from aerobic to anaerobic conditions (Custers effect). Antonie Van Leeuwenhoek 1984, 50, 183-192. [CrossRef]

33. Li, H.; Zhong, Y.; Lu, Q.; Zhang, X.; Wang, Q.; Liu, H.; Diao, Z.; Yao, C.; Liu, H. Co-cultivation of Rhodotorula glutinis and Chlorella pyrenoidosa to improve nutrient removal and protein content by their synergistic relationship. RSC Adv. 2019, 9, 14331-14342. [CrossRef]

34. Ling, J.; Nip, S.; Cheok, W.L.; Alves de Toledo, R.; Shim, H. Lipid production by a mixed culture of oleaginous yeast and microalga from distillery and domestic mixed wastewater. Bioresour. Technol. 2014, 173, 132-139. [CrossRef]

35. Zuccaro, G.; Pirozzi, D.; Yousuf, A. Lignocellulosic biomass to biodiesel. In Lignocellulosic Biomass to Liquid Biofuels; Academic Press: Cambridge, MA, USA; Elsevier: Amsterdam, The Netherlands, 2020; pp. 127-167.

36. Miazek, K.; Remacle, C.; Richel, A.; Goffin, D. Effect of lignocellulose related compounds on microalgae growth and product biosynthesis: A review. Energies 2014, 7, 4446-4481. [CrossRef]

37. Bajguz, A.; Czerpak, R.; Piotrowska, A.; Polecka, M. Effect of isomers of hydroxybenzoic acid on the growth and metabolism of Chlorella vulgaris Beijerinck (Chlorophyceae). Acta Soc. Bot. Pol. 2001, 70, 253-259. [CrossRef]

38. Larson, L.J. Effect of phenolic acids on growth of Chlorella pyrenoidosa. Hydrobiologia 1989, 183, 217-222. [CrossRef]

39. Larsson, S.; Palmqvist, E.; Hahn-Hägerdal, B.; Tengborg, C.; Stenberg, K.; Zacchi, G.; Nilvebrant, N.O. The generation of fermentation inhibitors during dilute acid hydrolysis of softwood. Enz. Microb. Technol. 1988, 24, 151-159. [CrossRef]

40. Cea Barcia, G.E.; Imperial Cervantes, R.A.; Torres Zuniga, I.; van Den Hende, S. Converting tequila vinasse diluted with tequila process water into microalgae-yeast flocs and dischargeable effluent. Bioresour. Technol. 2020, 300, 122644. [CrossRef]

41. Gong, Z.; Zhou, W.; Shen, H.; Yang, Z.; Wang, G.; Zuo, Z.; Huo, Y.; Zhao, Z.K. Co-fermentation of acetate and sugars facilitating microbial lipid production on acetate-rich biomass hydrolysates. Bioresour. Technol. 2016, 207, 102-108. [CrossRef] [PubMed]

42. Russell, J.B. Another explanation for the toxicity of fermentation acids at low pH: Anion accumulation versus uncoupling. J. Appl. Bacteriol. 1992, 73, 363-370. [CrossRef]

43. Anschau, A.; Xavier, M.C.; Hernalsteens, S.; Franco, T.T. Effect of feeding strategies on lipid production by Lipomyces starkeyi. Bioresour. Technol 2014, 157, 214-222. [CrossRef]

44. Gong, Z.; Wang, Q.; Shen, H.; Hu, C.; Jin, G.; Zhao, Z.K. Co-fermentation of cellobiose and xylose by Lipomyces starkeyi for lipid production. Bioresour. Technol. 2012, 117, 20-24. [CrossRef]

45. Yang, X.B.; Jin, G.J.; Gong, Z.W.; Shen, H.W.; Song, Y.H.; Bai, F.W.; Zhao, Z.B.K. Simultaneous utilization of glucose and mannose from spent yeast cell mass for lipid production by Lipomyces starkeyi. Bioresour. Technol. 2014, 158, 383-387. [CrossRef] 
46. Pirozzi, D.; Ausiello, A.; Yousuf, A.; Zuccaro, G.; Toscano, G. Exploitation of oleaginous yeasts for the production of microbial oils from agricultural biomass. Chem. Eng. Trans. 2014, 37, 469-474.

47. Probst, K.V.; Vadlani, P.V. Production of single cell oil from Lipomyces starkeyi ATCC 56304 using biorefinery by-products. Bioresour. Technol. 2015, 198, 268-275. [CrossRef]

48. Matsakas, L.; Sterioti, A.A.; Rova, U.; Christakopoulos, P. Use of dried sweet sorghum for the efficient production of lipids by the yeast Lipomyces starkeyi CBS 1807. Ind. Crop. Prod. 2014, 62, 367-372. [CrossRef]

49. Liu, L.; Chen, J.; Lim, P.-E.; Wei, D. Enhanced single cell oil production by mixed culture of Chlorella pyrenoidosa and Rhodotorula glutinis using cassava bagasse hydrolysate as carbon source. Bioresour. Technol. 2018, 255, 140-148. [CrossRef] [PubMed]

50. Qin, L.; Wei, D.; Wang, Z.; Alam, M.A. Advantage assessment of mixed culture of Chlorella vulgaris and Yarrowia lipolytica for treatment of liquid digestate of year industry and cogeneration of biofuel feedstock. Appl. Biochem. Biotechnol. 2019, 187, 856-869. [CrossRef]

51. Zhang, Z.; Pang, Z.; Xu, S.; Wei, T.; Song, L.; Wang, G.; Zhang, J.; Yang, X. Improved carotenoid productivity and COD removal efficiency by co-culture of Rhodotorula glutinis and Chlorella vulgaris using starch wastewaters as raw material. Appl. Biochem. Biotechnol. 2019, 189, 193-205. [CrossRef]

52. Liu, Y.; Wang, Y.; Liu, H.; Zhang, J. Enhanced lipid production with undetoxified corncob hydrolysate by Rhodotorula glutinis using a high cell density culture strategy. Bioresour. Technol. 2015, 180, 32-39. [CrossRef]

53. Younes, S.; Bracharz, F.; Awad, D.; Qoura, F.; Mehlmer, N.; Brueck, T. Microbial lipid production by oleaginous yeasts grown on Scenedesmus otusiusculus microalgae biomass hydrolysate. Bioprocess. Biosyst. Eng. 2020, 43, 1629-1638. [CrossRef]

54. Wang, S.; Wu, Y.; Wang, X. Heterotrophic cultivation of Chlorella pyrenoidosa using sucrose as the sole carbon source by co-culture with Rhodotorula glutinis. Bioresour. Technol. 2016, 220, 615-620. [CrossRef] [PubMed]

55. Iasimone, F.; Zuccaro, G.; D’Oriano, V.; Franci, G.; Galdiero, M.; Pirozzi, D. Combined yeast and microalgal cultivation in a pilot-scale raceway pond for urban wastewater treatment and potential biodiesel production. Water Sci. Technol. 2018, 77, 1062-1071. [CrossRef]

56. Tkachenko, A.F.; Tigunova, S.M.; Shulga, S.M. Microbial lipids as a source of biofuel. Cytol. Genet. 2013, 47, 343-348. [CrossRef]

57. Stansell, G.R.; Gray, V.M.; Sym, S.D. Microalgal fatty acid composition: Implications for biodiesel quality. J. Appl. Phycol. 2011, 24, 791-801. [CrossRef]

58. Parsons, S.; Allen, M.; Chuck, C.J. Coproducts of algae and yeast-derived single cell oils: A critical review of their role in improving biorefinery sustainability. Bioresour. Technol. 2020, 303, 122862. [CrossRef]

59. Asraful, A.M.; Masjuki, H.H.; Kalam, M.A.; Rizwanul Fattah, I.M.; Imtenan, S.; Shahir, S.A.; Mobarak, H.M. Production and comparison of fuel properties, engine performance, and emission characteristics of biodiesel from various non-edible vegetable oils: A review. Energy Convers. Manag. 2014, 80, 202-228. [CrossRef] 